\title{
A conceptually new treatment approach for relapsed glioblastoma: Coordinated undermining of survival paths with nine repurposed drugs (CUSP9) by the International Initiative for Accelerated Improvement of Glioblastoma Care.
}

Richard E. Kast ${ }^{1}$, John A. Boockvar ${ }^{2}$, Ansgar Brüning ${ }^{3}$, Francesco Cappello ${ }^{4}$, Wen-Wei Chang ${ }^{5}$, Boris Cvek ${ }^{6}$, Q. Ping Dou7, Alfonso Duenas-Gonzalez ${ }^{8}$, Thomas Efferth $^{9}$, Daniele Focosi ${ }^{10}$, Seyed H. Ghaffari ${ }^{11}$, Georg Karpel-Massler ${ }^{12}$, Kirsi Ketola ${ }^{13}$, Alireza Khoshnevisan ${ }^{14}$, Daniel Keizman ${ }^{15}$, Nicolas Magné ${ }^{16}$, Christine Marosi $^{17}$, Kerrie McDonald ${ }^{18}$, Miguel Muñoz ${ }^{19}$, Ameya Paranjpe ${ }^{20}$, Mohammad $\mathbf{H}$. Pourgholami ${ }^{18}$, Iacopo Sardi ${ }^{21}$, Avishay Sella ${ }^{22}$, Kalkunte S. Srivenugopal20, Marco Tuccori $^{10}$, Weiguang Wang ${ }^{23}$, Christian R. Wirtz ${ }^{12}$, Marc-Eric Halatsch ${ }^{12}$

${ }^{1}$ IIAIGC Headquarters, Dean of Studies, Burlington, VT, USA

${ }^{2}$ Weill Cornell Medical College, NY, USA

3 University of München, München, Germany

${ }^{4}$ University of Palermo, Palermo, Italy

${ }^{5}$ Chung Shan Medical University Hospital, Taichung, Taiwan

${ }^{6}$ Palacky University, Olomouc, Czech Republic

7 Wayne State University, Detroit, USA

${ }^{8}$ Instituto de Investigaciones Biomedicas UNAM, Instituto Nacional de Cancerología, Mexico City, Mexico

9 Johannes Gutenberg University, Mainz, Germany

${ }^{10}$ University of Pisa, Pisa, Italy

${ }^{11}$ Tehran University of Medical Sciences, Tehran, Iran

12 University of UIm, Ulm, Germany

13 University of British Columbia, Vancouver, Canada

${ }^{14}$ Shariati Hospital, Tehran University of Medical Sciences, Tehran, Iran

15 Oncology Department, Meir Medical Center, Tel Aviv University, Israel

${ }^{16}$ Institut de Cancérologie Lucien Neuwirth, Saint-Priest en Jarez, France

${ }^{17}$ Medical University of Vienna, Wein, Austria

18 University of New South Wales, Sydney, Australia

${ }^{19}$ Virgen del Rocío University Hospital, Sevilla, Spain

${ }^{20}$ Texas Tech University Health Sciences Center, Amarillo, USA

${ }^{21}$ Meyer Children's Hospital, Firenze, Italy

${ }^{22}$ Assaf Harofeh Medical Center, Zerifin, Israel

23 University of Wolverhampton, Wolverhampton, UK

Correspondence to: Richard E. Kast, email: richarderickast@gmail.com

Marc-Eric Halatsch , email: Marc-Eric.Halatsch@uniklinik-ulm.de

Keywords: angiotensin, aprepitant, artesunate, auranofin, captopril, cytokines, disulfiram, glioblastoma, ketoconazole, nelfinavir, neurokinin, sertraline, temozolomide

Received: April 7, $2013 \quad$ Accepted: April 11, $2013 \quad$ Published: April 13, 2013

This is an open-access article distributed under the terms of the Creative Commons Attribution License, which permits unrestricted use, distribution, and reproduction in any medium, provided the original author and source are credited. 


\section{ABSTRACT:}

To improve prognosis in recurrent glioblastoma we developed a treatment protocol based on a combination of drugs not traditionally thought of as cytotoxic chemotherapy agents but that have a robust history of being well-tolerated and are already marketed and used for other non-cancer indications. Focus was on adding drugs which met these criteria: a) were pharmacologically well characterized, b) had low likelihood of adding to patient side effect burden, c) had evidence for interfering with a recognized, well-characterized growth promoting element of glioblastoma, and d) were coordinated, as an ensemble had reasonable likelihood of concerted activity against key biological features of glioblastoma growth. We found nine drugs meeting these criteria and propose adding them to continuous low dose temozolomide, a currently accepted treatment for relapsed glioblastoma, in patients with recurrent disease after primary treatment with the Stupp Protocol. The nine adjuvant drug regimen, Coordinated Undermining of Survival Paths, CUSP9, then are aprepitant, artesunate, auranofin, captopril, copper gluconate, disulfiram, ketoconazole, nelfinavir, sertraline, to be added to continuous low dose temozolomide. We discuss each drug in turn and the specific rationale for use- how each drug is expected to retard glioblastoma growth and undermine glioblastoma's compensatory mechanisms engaged during temozolomide treatment. The risks of pharmacological interactions and why we believe this drug mix will increase both quality of life and overall survival are reviewed.

Preamble: ecce turtur. ipse proficit tantum con collum foras.

\section{INTRODUCTION}

In the effort to improve the current prognosis in glioblastoma of one or two years' survival after primary diagnosis even with the best of treatments, we have created a new adjuvant approach, termed CUSP9, presented here. As of early 2013, standard initial treatment consists of temozolomide and irradiation after maximal primary resection, typically referred to as the "Stupp Protocol" $[1,2]$. There is no standard or agreed upon single best approach to recurrent glioblastoma after this initial treatment. A total of 22 clinical trials reported in 2012, all using various new, recurrent glioblastoma treatments that all had sound established activity in preclinical study [1, 3 - 23]. Yet none reported more than minimal quality of life (QOL) or overall survival (OS) benefit. Many were stopped early for increased morbidity, drastically decreased QOL, or for meeting pre-established futility criteria.

Dörner et al. recently reported that even after placement of carmustine (BCNU) wafers along the surgical cavity wall, the recurrence pattern remains largely local with meager meaningful advantages to patients in OS or QOL increases [24]. We present here a position paper from The International Initiative for Accelerated Improvement of Glioblastoma Care on a treatment plan aiming for more lasting tumor control while not adding to patients' side effect burdens. Our treatment plan- termed CUSP9- aims to increase QOL and OS compared to current recurrent glioblastoma treatments by adding nine already-marketed growth factor-inhibiting drugs to low dose continuous temozolomide.

We review here the rationale for this nine drug mix using already-marketed drugs, as adjuvants to improve effectiveness and tolerability of low dose continuous temozolomide in treatment of glioblastoma at first postStupp protocol recurrence. The total ten drugs of CUSP9 are in three function categories:

i] Established use in recurrent glioblastomatemozolomide,

ii] Sound pre-clinical evidence supporting potential benefit based on documented inhibition of growth factors or a pathogenic driver- aprepitant, artesunate, auranofin, disulfiram with copper gluconate, nelfinavir,

iii] Published reports of increased OS with use but of uncertain significance and drugs with less robust theoretical support- captopril, sertraline, ketoconazole

As many growth enhancing systems have been identified in glioblastoma, and many currently-marketed drugs not traditionally thought of as cytotoxic have shown to have inhibitory activity at one or another of these systems, we searched the literature to find such drug- glioblastoma growth factor matches that would be unlikely to add to patient side effect burden based on our experience of long use of the respective drug in humans for non-cancer indications. Drugs were selected also on the basis of having little potential for seriously aversive effect or interaction with each other and, as an ensemble, had reasonable likelihood of concerted and coordinated activity against key biological features of glioblastoma growth. In the Conclusion section, we outline why CUSP9 
can be expected to improve QOL as well versus current simpler treatments.

Pharmacologic risks of each drug individually and permutations of all possible combinations were carefully evaluated and presented in section IV. CUSP9 PHARMACOLOGY. The only potential for harmful interaction that we can foresee is the potential interaction between artesunate and auranofin. We believe this risk can be managed by slow up titration of doses and frequent monitoring as described in section V. Partial CUSP's, Risk Reduction, Risk Assessment. Otherwise the risks of these drugs used together was assessed to be low with the understanding that unexpected interactions may occur and this risk will require exceptional vigilance, as with any new treatment but particularly so in a regimen of this complexity.

There is now broad recognition that multiple crosscovering growth promoting signaling paths and cell death avoiding mechanisms are active in glioblastoma [25-30]. As Siegelin et al. stated in referring to glioblastoma, "Drug discovery for complex and heterogeneous tumors now aims at dismantling global networks of disease maintenance" [29]. Or as formulated by Eyler et al. also referring to glioblastoma, these "networks of disease maintenance" require commensurate corresponding efforts directed to understanding "the exact nature by which many of the pathogenic drivers connect" [30]. On this basis we generate CUSP9. The conclusion of recognition of many global networks and multiple pathogenic drivers is the requirement for many pathogenic drivers' inhibitors as CUSP9 provides.

Multiple pathogenic drivers and interconnected growth promoting paths of glioblastoma maintenance

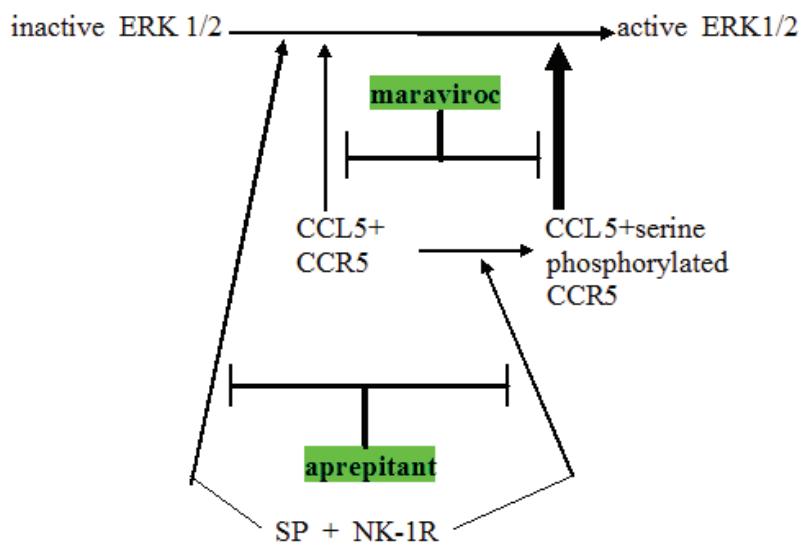

Figure 1: Schema showing relationship between CCR5 and neurokinin receptor (NK-1R) signaling operative in glioblastoma. Note three points: (a) NK-1R signaling can augment CCR5 signaling by converting less active plain CCR5 to the more active serine phosphorylated CCR5, (b) NK-1R and CCR5 can cross-cover for each other, both independently can activating ERK1/2 and (c) expected synergy between aprepitant and maraviroc in blocking this aspect of glioblastoma growth promotion. Maraviroc is a newly approved blocking drug at the CCR5 cytokine receptor. are concepts reminiscent of a well-known problem in medicine, expressed as a metaphor- "The Three Locks Problem". A door with three locks will not open any better if one or two of the locks are unlocked. Likewise blocking one or two growth factors may not result in any slowing of glioblastoma growth due to alternate paths that take over for the blocked one[s]. How do we proceed if glioblastoma has twenty locks on it? In logic terms "if A then not B" does not imply "if not A then B" [if growth path "A" remains active then glioblastoma won't be stopped ("not $\mathrm{B}$ ") does not imply that if growth path " $\mathrm{A}$ " is effectively inhibited then glioblastoma will be stopped ("B")].

Table 1. lists the drugs of CUSP9 with basic area of projected modes of action.

\section{RATIONALE:}

\section{II.1. Established use in recurrent glioblastoma- temozolomide}

Temozolomide is a $194 \mathrm{Da}$ alkylating cytotoxic cancer chemotherapy drug. Current standard primary glioblastoma treatment, the Stupp Protocol, is, with minor variations, temozolomide and irradiation to tumor area after maximal resection that spares areas vital to good QOL $[1,2,31,32]$. There is no generally accepted standard treatment for glioblastoma that has recurred after Stupp Protocol treatment. Our plan is to give temozolomide $50 \mathrm{mg} / \mathrm{m}^{2}$ daily without pause (or until toxicity) at first recurrence after a completed Stupp Protocol. Multiple other first recurrence treatments have been reported but none have exceeded the QOL maintenance and a median OS of 30 to 41 weeks that this regimen provides [2, 33, 34].

\section{II.2. Sound pre-clinical evidence supporting potential benefit based on documented growth factor or a pathogenic driver's inhibition- aprepitant, artesunate, auranofin, disulfiram, nelfinavir.}

\section{II.2.1. aprepitant.}

Aprepitant is a 534 Da oral neurokinin-1 receptor (NK-1R) antagonist approved for use in treating chemotherapy induced nausea and vomiting (CINV), an indication for which it is quite safe and effective [35, 36], even during highly emetogenic regimes [36-40]. Substance $P$ is an eleven amino acid signaling neuropeptide that belongs to the tachykinin family of peptides. Substance $P$ is the natural ligand of NK-1R that by binding to NK-1R, in addition to generating CINV, forms a regulatory link in many biological functions in cancer such as proliferation, angiogenesis, migration, and metastasis. 
Table 1: Summary of CUSP9, listing the drugs with a short unreferenced description of the rationale or expected advantage accruing from its use. References are given in the text.

\begin{tabular}{|l|l|}
\hline DRUG & EXPECTED BENEFIT \\
\hline aprepitant & Nausea reduction, inhibit growth by blocking NK-1R \\
\hline artesunate & Increase ROS, empirical anti-glioma effects, survivin inhibition \\
\hline sertraline & Empirical longer OS, improved mood, documented anti-proliferation effect in glioma cells \\
\hline captopril & $\begin{array}{l}\text { Empirical longer OS, MMP-2 \& MMP-9 inhibition, prevents AT-2 stimulation, lowers IL-18 } \\
\text { stimulated VEGF, TNF, \& IL-8 }\end{array}$ \\
\hline auranofin & $\begin{array}{l}\text { Thioredoxin reductase inhibition, cathepsin B inhibition, increased i.c. ROS, empirical [\& } \\
\text { potentially dangerous] synergy with artesunate, }\end{array}$ \\
\hline nelfinavir & $\begin{array}{l}\text { HSP90 inhibition, MMP-2 \& MMP-9 inhibition, decreased signaling at multiple receptors, i.a. } \\
\text { TGF-beta, increased i.c. ROS, decreased AKT activation, lower VEGF, IL-8, ICE inhibition }\end{array}$ \\
\hline temozolomide & A common \& accepted treatment for recurrent glioblastoma \\
\hline disulfiram & $\begin{array}{l}\text { ALDH inhibition, glutathione inhibition, increase ROS, lowers IL-18 stimulated VEGF, TNF, } \\
\text { \& IL-8, MMP-2 \& MMP-9 inhibition, proteosome inhibition, SOD inhibition, P-glycoprotein } \\
\text { inactivation, MGMT inhibition. }\end{array}$ \\
\hline Cu gluconate & Adequate Cu may be a requirement for disulfiram activity \\
\hline ketoconazole & $\begin{array}{l}\text { Drug efflux inhibitor at BBB, permits higher brain ritonavir (or nelfinavir) concentrations, } \\
\text { 5-lipoxygenase inhibitor, thromboxane synthase inhibitor, empirical anti-glioma effect }\end{array}$ \\
\hline
\end{tabular}

Muñoz et al. [41, 42] have been documenting in a series of articles the growth enhancing aspects of NK1R signaling in several cancers over the last few years. They have been advocating trials of aprepitant in an anticancer role in these cancers. Since many cancers $[43,44]$, including glioblastoma [45] use Substance P signaling at NK-1R as a growth stimulating element it was logical enough to suggest aprepitant as treatment adjunct $[46,47]$. An added benefit of aprepitant is the rarity of any side effect at all when used as treatment for CINV [37].

Empirically, Substance P stimulates glioma cells' proliferation [45]. NK-1R antagonists such as aprepitant, after binding to NK-1R, inhibit proliferation, have proapoptotic effects, and exert anti-angiogenic and antimigration effects in pre-clinical models [42, 44, 48].

Aprepitant has central effects and good diffusion across the blood brain barrier (BBB). Moreover, it is eminently well tolerated $[36,37]$ even in a clinical trial as antidepressant using $300 \mathrm{mg} /$ day. Side effects did not differentiate from placebo [49].

Considering the above data sets, plus the fact that glioma cells tend to overexpress NK-1R [50] and aprepitant shows a broad spectrum antitumor action, including in glioma models, it was natural to add aprepitant to CUSP9.

\section{II.2.2. artesunate.}

Artesunate is a $384 \mathrm{Da}$ orally available drug used in tablets alone or in fixed combinations with other drugs to treat malaria, particularly with drug-resistant Plasmodia strains, around the world and usually without a prescription [51]. Artesunate is one of several related semi-synthetic phytoderrived drugs, the artemisinin's, based on Artemisia annua, an herb used in Chinesse traditional medicine. In aggregate, worldwide artesunate consumption is massive.

As part of a screening campaign of the National Cancer Institute, USA, artesunate and other related artemisinin-type compounds were shown to have cytotoxicity towards 60 cell lines derived from 8 different tumor types, including CNS tumors [52]. That artesunate induces apoptosis in cancer cells was first shown by Efferth et al. in a leukemia cell line [53].

That there was no correlation between $\mathrm{IC}_{50}$ values of artesunate and mRNA expression of the multidrug resistance-conferring $\mathrm{ABCB} 1$ gene (coding for P-glycoprotein efflux pump) in the National Cancer Institute cancer cell lines and that artesunate is similarly active towards cell lines which over-expressing MDR1/ P-glycoprotein [54-56] indicate that artesunate isn't a substrate for these chemotherapy defeating elements. Likewise, methotrexate-resistant cells with an amplified dihydrofolate reductase gene and hydroxyurea-resistant cells over-expressing ribonucleotide reductase were not cross-resistant to artesunate [56].

Particularly beneficial for glioblastoma treatment, the transfer of dihydroartemisinin, the first metabolite of artesunate, from plasma to lipid-rich brain structures is still increasing at a time when post-dose blood levels of both artesunate and dihydroartemisinin are decreasing in humans with malaria treated with artesunate [57].

A rough correlation of baseline antioxidant mRNA gene expression in the National Cancer Institute cancer cell lines with the $\mathrm{IC}_{50}$ values for artesunate indicated a role of reactive oxygen species (ROS) stress in artesunate's anti-cancer effect [58-60]. WEHI7.2 cells selected for 
resistance to hydrogen peroxide or transfected with thioredoxin (note strong thioredoxin reductase inhibition by another member of CUSP9, auranofin discussed below, see also Figs. 2. and 6.), manganese superoxide dismutase (that is inhibited by another CUSP9 member, disulfiram discussed below) or catalase were relatively artesunateresistant compared to parental cells [58].

As tumor cells commonly contain more iron than corresponding normal cells, the question arises as to whether iron may be critical for artemisinin group medicines' action towards tumor cells. Cellular iron uptake and internalization are mediated in part by binding of transferrin-iron complexes to a transferrin receptor (CD71) on the cell surface membrane [61].

CD71 is highly expressed in tumors, including glioblastoma [62, 63]. CD71 expression was higher in a leukemia cell line and in U373 glioma tumor cells (48-95\%) than in peripheral mononuclear blood cells of healthy donors $(<2 \%)$ [64]. Iron and transferrin increased cytotoxicity of artesunate and artemisinin towards these cell lines [64].

Interestingly, exposure of artemisinin and its derivatives produced only marginal cytotoxicity to non-tumor cells [64, 65]. The growth of primary human fibroblasts was almost unaffected by artesunate concentrations up to $100 \mu \mathrm{M}[64,65]$. The elegance of this approach of Efferth et al. is that it uses glioblastoma's hunger for growth as reflected in CD71 overexpression, an erstwhile growth enhancing attribute, to help kill these cells.

Artesunate also induces DNA breakage in a dose-dependent manner as shown by single-cell gel electrophoresis and confocal microscopy of the DNA double-strand break indicator gamma-H2AX [53, 66]. This is probably the proximate mode of damage leading to artesunate mediated cell death.

The epidermal growth factor receptor (EGFR, also known as HER-1) is an important target for cancer therapy and is particularly important specifically in glioblastoma pathophysiology [67-69]. Artesunate strongly enhanced erlotinib cytotoxicity to glioblastoma cells [70]. Artesunate enhanced cytotoxicity of doxorubicin in human acute T cell leukemia Jurkat cell line J16 and the human acute lymphoblastic leukemia cell lines CEM and Molt4 [71]. Exposure of glioma cells to artesunate enhanced irradiation induced induction of apoptosis, G2/M arrest and DNA damage [72] and had similar effects in a nonsmall cell lung cancer cell line [73].

\section{II.2.3. auranofin.}

Auranofin is a $678 \mathrm{Da}$ drug approved to treat rheumatoid arthritis $[74,75]$. Three sets of data suggest its use in adjuvant treatment of glioblastoma.

One of the probable mechanisms of action of auranofin in promoting cytotoxic drug cell death is given in Fig. 2. Anti-TNF-alpha-induced apoptosis protein (ATIA) is highly expressed in human glioblastoma [76]. ATIA knockdown in glioblastoma cells renders them sensitive to hypoxia-induced apoptosis. As shown in Fig. 2, ATIA up regulates thioredoxin reductase [76], a cytoprotective factor reducing intracellular ROS. As outlined below, it is precisely by inhibiting such cytoprotective thioredoxin reductase that we think auranofin exerts its primary anticancer effect. Strong thioredoxin reductase inhibition

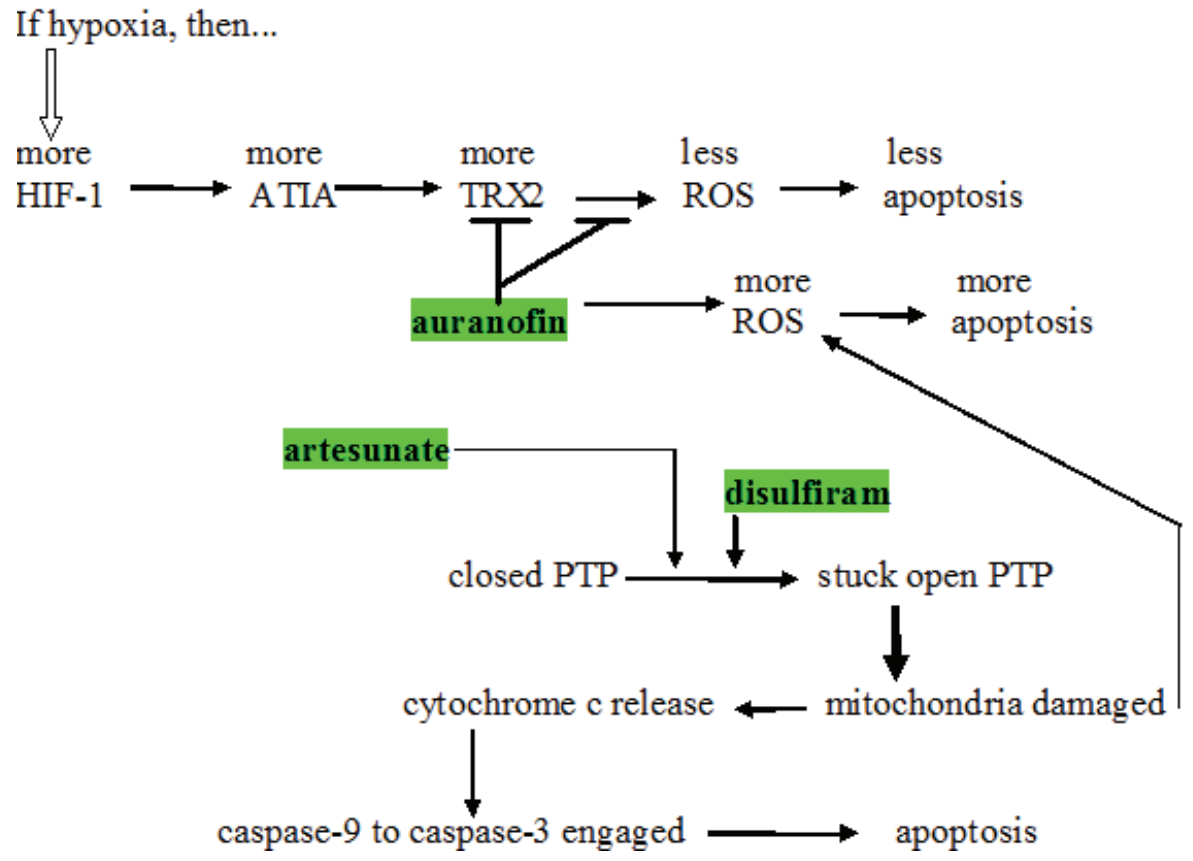

Figure 2: Schema showing several places where artesunate, auranofin, and disulfiram act to increase intracellular oxidative stress. induced apoptosis protein ; ROS = reactive oxygen species; TRX-2 = thioredoxin reductase; HIF-1 = hypoxia induced factor-1; ATIA = anti-TNF-alpha-induced apoptosis; PTP = mitochondrial outer membrane permeability transition pore. 
by auranofin is well-documented [77]. Mean circulating blood thioredoxin reductase levels were $31 \%$ higher in glioblaastoma patients compared to matched controls [78], indicating a significant pathophysiological role for thioredoxin reductase. Glioblastoma tissue levels of thioredoxin reductase were five times that of normal brain [78].

Shifting cancer cells' redox bias towards oxidizing, away from reducing is an active area of cancer research. As a major force in limiting oxidizing conditions within cells, thioredoxin reductase therefore becomes an attractive target in cancer treatment generally. Auranofin and other thioredoxin reductase inhibitors are in active research programs as adjunct to current cancer treatment $[79,80]$. How thioredoxin reductase inhibition by auranofin shifts intracellular redox towards an oxidizing state is diagrammed in Fig. 6. Increased intracellular ROS generated by auranofin has been shown empirically [ 81 , 82].

Multiple experimental thioredoxin reductase inhibitors other than auranofin are in various stages of development for cancer treatment after showing good pre-clinical activity $[83,84]$. We intend to use the one we already have- auranofin.

As diagrammed in Fig. 6, NADP $(\mathrm{H})$ is required for regeneration of reduced thioredoxin. Reduced thioredoxin is a major intracellular reducing agent. Glioma cell line proliferation remains unchanged as intracellular NADP $(\mathrm{H})$ levels decrease until a level $\sim 15 \%$ of normal is reached. At further decreases beyond that point proliferation and motility become progressively impaired and viability steeply declines as levels descend through $<10 \%$ of normal [85].

We have empirical evidence of auranofin's cytotoxicity in multiple cancer models [86], for example ovarian cancer [87], head \& neck cancer [88] and others.

Cathepsin B is an important element of glioblastoma cell invasion along Scherer's tracts [89, 90]. Two independent groups found that heavier cathepsin B immunohistochemical staining predicts shorter glioblastoma OS [91, 92]. Experimental reduction of cathepsin B inhibited glioblastoma growth and invasion in rodent glioblastoma models [93]. Auranofin inhibits cathepsin B and was previously suggested as a glioblastoma treatment adjunct on that basis [94].

\section{II.2.4. disulfiram.}

Of all the ancillary drugs of CUSP9, disulfiram has the strongest evidence of potential benefit in glioblastoma. Disulfiram is a 297 Da oral aldehyde dehydrogenase (ALDH) inhibitor that results in accretion of acetaldehyde if ethanol is ingested. Such high levels of acetaldehyde are experienced as extremely unpleasant, hence alcohol consumption is discouraged, the current main clinical use of disulfiram. It has been in continuous use in the treatment of alcoholism since the 1940's [95].

After ingestion disulfiram is rapidly metabolized to diethyldithiocarbamate after binding copper in the stomach [96]. Disulfiram metabolism is complex [96] and the ultimate metabolic species relevant to ALDH inhibition or disulfiram's anti-cancer effects remain uncertain. In clinical use by far the most common observation is to see no side effects at all in those patients taking disulfiram $250 \mathrm{mg}$ p.o. once or twice a day to treat alcoholism. An estimated $10 \%$ will experience an easily tolerated metallic taste at times.

Much of the seminal work on disulfiram's anticancer cell properties come from the lab of Weiguang Wang at the University of Wolverhampton [97-101]. Disulfiram's multiple anticancer properties have been demonstrated in pre-clinical models of breast, prostate, myeloma, leukemia, lung cancers, cervical adenocarcinoma, melanoma, neuroblastoma and colorectal cancer [102-112].

Disulfiram exerts significant anticancer activity in

\begin{tabular}{|l|l|l|l|l|l|l|l|l|l|}
\hline sert & - & & & & & & & & \\
\hline cap & - & - & & & & & & & \\
\hline Au & - & - & - & & & & & & \\
\hline NFV & PK & - & - & - & & & & & \\
\hline TMZ & - & - & - & - & PD & & & & \\
\hline DSF & - & - & - & - & - & - & & & \\
\hline $\mathrm{Cu}$ & - & - & - & - & - & - & - & & \\
\hline ket & PK & - & - & - & PD & PD & - & - & \\
\hline art & - & - & - & PD & PK & - & - & - & PK \\
\hline Drugs & apr & sert & cap & Au & NFV & TMZ & DSF & Cu & ket \\
\hline
\end{tabular}

Figure 3: Grid of potential foreseeable interactions of CUSP9 drugs. We recognize that unexpected interactions are not ruled out by this grid but the literature review behind this grid does make untoward reactions less likely. apr, aprepitant; sert, sertraline; cap, captorpil; Au, auranofin; NFV, nelfinavir; TMZ, temozolomide; DSF, disulfiram; cap, captopril; Cu, copper gluconate; ket, ketoconazole; art, artesunate; PK: potential pharmacokinetic interaction; PD: potential pharmacodynamic interaction 
multiple contexts [112-118]. Particularly the stem cell sub-population of glioblastoma are ALDH positive [97, $98,120-123]$, and susceptible to inhibition by disulfiram [97, 98, 100, 120-124]. We have increasing pre-clinical evidence that disulfiram, an old and inexpensive drug in continuous use for 6 decades in alcohol aversion therapy exerts significant anticancer activity [104, 112-118].

Disulfiram has previously been documented to potentiate the effect of several chemotherapy agents in vitro: cisplatin [128], gemcitabine [101, 129] temozolomide [130], paclitaxel [100], docetaxel [131], cyclophosphamide [132], 5-fluorouracil [101, 102], doxorubicin [99], sunitinib [104], and BCNU [133]. Currently, disulfiram is in Phase I clinical trials in metastatic melanoma, in hormone refractory cancers with lung and liver metastases (www. clinicaltrials.gov, identifiers NCT00256230 and NCT00742911) as well as in prostate cancer (identifier: NCT01118741).

Dufour et al. randomized 64 women with non-metastatic high risk breast cancer in a double blind placebo controlled phase 3 clinical trial of adjuvant diethyldithiocarbamate vs. placebo [134]. Diethyldithiocarbamate $10 \mathrm{mg} / \mathrm{kg}$ p.o. or placebo was given once weekly for 9 months after the first chemotherapy cycle. After 6 years, overall survival was $81 \%$ in the diethyldithiocarbamate group vs. $55 \%$ in placebo group, a significant difference. Current recommended dosing of disulfiram during alcoholism treatment is $250-500 \mathrm{mg}$ per day, equivalent to $3500 \mathrm{mg}$ of diethyldithiocarbamate weekly compared to the $\sim 700$ $\mathrm{mg}$ of diethyldithiocarbamate weekly given in the Dufour et al. trial [134]. Even at $3000 \mathrm{mg}$ p.o. per day disulfiram gave no serious adverse effects (135).

A detail-poor case report appeared in 1977 of a woman experiencing gradual remission of breast cancer metastases to spine, skull, pelvis and ribs after intermittent exposure to disulfiram and interspersed drinking bouts (136). She died from a fall after ten years of such intermittent, alternating (and overlapping?) alcoholdisulfiram exposure. Autopsy showed high blood alcohol level and microscopic nests of metastatic breast cancer in her bone marrow but no macroscopic disease [136].

A case report of a patient with metastatic ocular melanoma treated with disulfiram $250 \mathrm{mg} /$ day p.o. and zinc gluconate $250 \mathrm{mg}$ /day p.o. showed decreasing tumor volume [110]. After 53 months of ongoing treatment with disulfiram $(250 \mathrm{mg} / \mathrm{d})$ and zinc gluconate $(250 \mathrm{mg} / \mathrm{d})$ this patient experienced no progression with no discernible drug side effects [110].

Suppression of breast cancer xenografts by disulfiram was shown in mice (137). Multiple in vitro models have recently demonstrated considerable antiglioblastoma effects via proteasome and ALDH inhibitions $[97,98,111,115,122,130,138]$. Suppression of breast cancer xenografts by $74 \%$ was shown in mice [137]. In prostate cancer xenografts $40 \%$ reduction in growth was seen $[112,117]$ indicating that combinatorial approaches will be needed $[112,118]$. Following this conclusion

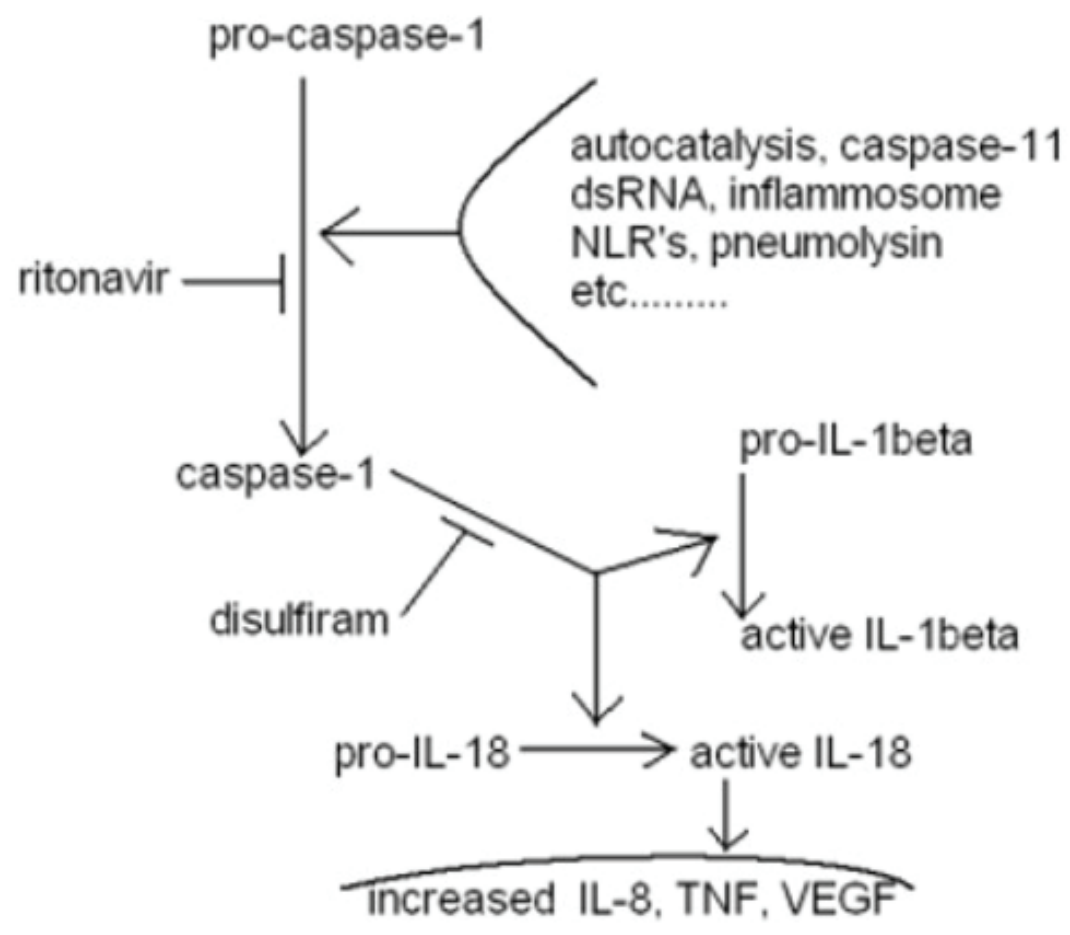

Figure 4: Diagram of another aspect of disulfiram + ritonavir of potential benefit to glioblastoma treatment effectiveness. Caspase- 1 is synonymous with ICE, interleukin- 1 converting enzyme. The diagram lists ritonavir. It remains unproven if nelfinavir will function similarly, although every indication so far is that it will. 
Ketola et al. found several compounds could potentiate disulfiram in reducing prostate cancer xenograft viability [104]. The vascular endothelial growth factor (VEGF) receptor kinase inhibitor sunitinib for example was synergistic with disulfiram [104].

Disulfiram also inactivates P-glycoprotein [139], a major drug exporter from the brain, and therefore a problem for us in delivering chemotherapeutic drugs to glioblastoma.

Antitumor efficacy specifically of temozolomide can be directly increased by disulfiram partially through inhibition of the DNA repair protein O6-methylguanineDNA methyltransferase (MGMT) [130, 140]. MGMT is expressed at low levels in human brain. It normally functions to remove methyl groups from methylguanine that if left uncorrected would be read as adenosine (the normal G:C becomes an A:T) [141, 142]. MGMT transfers the temozolomide-generated methyl groups bound to O6position of guanine directly to an active site cysteine (Cys145) in MGMT in a 1:1 stoichiometric reaction [143], permanently destroying the MGMT molecule that is then degraded after each single methylguanine demethylation [144]. Consistent with this, OS patients with MGMTproficient tumors is somewhat shorter than those with lower expression of MGMT [145, 146].

Lesions that escape MGMT-mediated removal are targeted by mismatch repair (MMR). During DNA replication temozolomide-induced unrepaired methylguanine mispairs with thymine. MMR removes thymine from these methylG- $T$ mispairs. As methylguanine is left unrepaired by MMR the methylguanine is again read as an adenosine and paired with thymidine. This becomes a futile repair cycle. This may result in single-strand DNA repair patches that block replication. In a subsequent round of replication, this eventually results in double-strand breaks that are potent activators of the apoptotic pathway [141, 142].

Inhibition of MGMT by O6-benzylguanine during temozolomide is undergoing clinical trials but frequent bone marrow toxicity is discouraging [147]. Due to its basic microenvironment MGMT's Cys145 has a low pKa of 4.8 [148]. Srivenugopal and his colleagues have found that disulfiram can form adducts with this Cys 145 at the active site of MGMT, thereby inactivating its methyltransferase function [144, 149]. Empirically disulfiram increases the cytotoxicity of another aklylating agent occasionaly used in glioblastoma treatment, BCNU (Paranjpe). From the foregoing, it is clear that the electrophilic drug disulfiram, a major component in the CUSP9 protocol, is expected to have multifaceted biochemical effects, all working in synergy to improve glioma treatment.

As highly reactive compounds, disulfiram and its first metabolite diethyldithiocarbamate react with many proteins in the cell, particularly by binding metals in enzymes' active sites [113-120]. This has made the

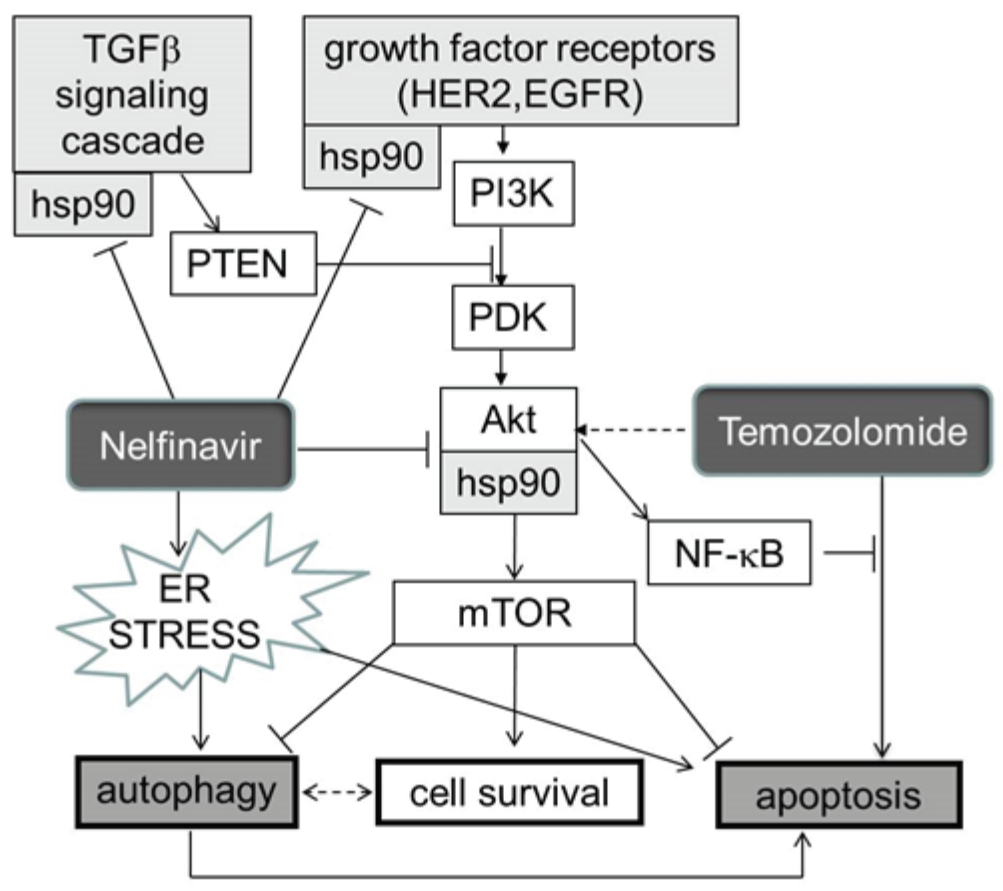

Figure 5: Schema indicating how HSP90, and hence its inhibition by nelfinavir (NFV) sit at several crossroads previously documented as crucial for glioblastoma growth. Note that CUSP9 is expected to inhibit the compensatory survivalenhancing response to temozolomide by two paths. A) as indicated in this Figure via nelfinavir dampening of AKT function, and B] by the NFkB degradative actions of disulfiram. Maintainance of a good NFkB pool is one of the crucial elements in glioblastoma hardiness [314]. 
determination of a primary mechanism of action in cancer treatment of disulfiram and its multiple metabolites difficult. Several non-exclusive mechanisms have been proposed based on demonstrated in vitro actions summarized below:

- $\quad$ inhibition of DNA methyltransferase [112],

- reduction of NF-kB activation [100-102, 111, $116,133,150]$,

- $\quad$ reduction of DNA replication [118],

- $\quad$ induction of oxidative stress $[100,117]$,

- induction of mitochondrial membrane permeabilization, cell cycle arrest, reduction of angiogenesis, invasion of cancer stem cells [100],

- $\quad$ proteosome inhibition [115-118, 137, 151], as inhibitor of superoxide dismutase with consequently increased intracellular reactive oxygen species [152],

- MGMT repair function inhibition [133, 144, 149]

- $\quad$ inhibition of interleukin-1 converting enzyme (ICE-1) as diagramed in Fig. 4 [153, 154].

- ALDH inhibition mediated decreases cancer stem cell function $[121,122,126,127,130$, 155]

- $\quad$ P-glycoprotein inactivation [139]

Which of these paths is important in disulfiram's clinical anti-cancer effect, which are primary and which secondary to some underlying primary effect, which are
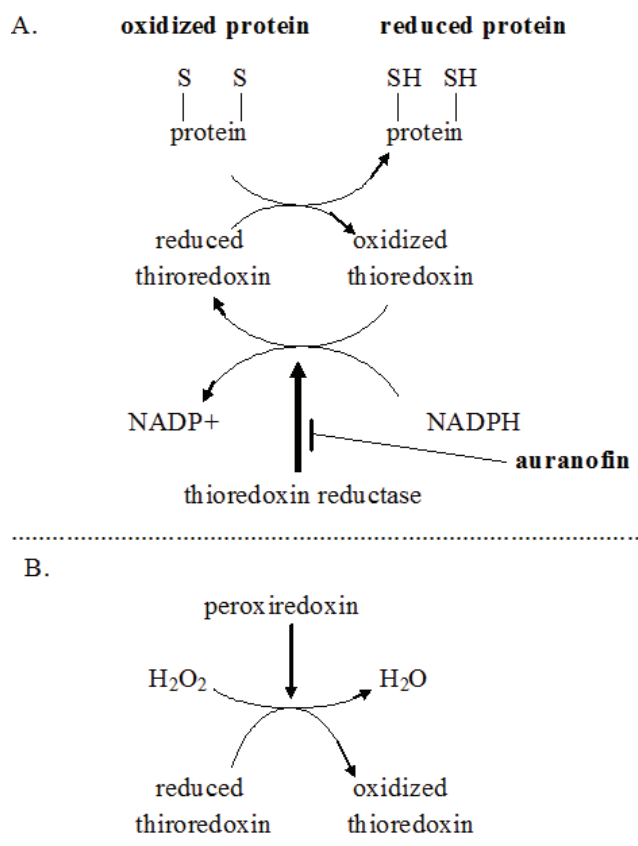

Figure 6: A. Schema showing auranofin shifting of intracellular redox towards an oxidizing state by diminishing regeneration of reduced thioredoxin. B. Schema showing related path by which thioredoxin reductase inhibition increases intracellular hydrogen peroxide $\left(\mathrm{H}_{2} \mathrm{O}_{2}\right)$. Particular importance of NADPH regeneration from NADP+ in glioblastoma metabolism and growth is reviewed in ref. 313 . simple epiphenomena, are all unanswered questions. Recent dramatic data from the lab of H. Ishii in Osaka indicate that ALDH enzymatic function itself is important for stem cell resistance to cytotoxic chemotherapy [155]. ALDH therefore is not just a marker for stemness. It is a mediator of stemness and most importantly, a mediator we can block.

Concordant with the data of H. Ishii's group and particularly encouraging for our intended use in CUSP9, Schäfer et al. have recently identified ALDH 1A1 isoform as a major marker (and mediator of) glioblastoma resistance to temozolomide [123]. We have ample reason to include disulfiram. In many ways disulfiram would seem to be the ideal adjuvant addition to current cytotoxic chemotherapies of cancer, including glioblastoma.

Since some data on disulfiram as adjunct during cancer treatment has indicated a requirement for copper [97-99, 101, 105, 116, 119, 122]. Copper gluconate is a 434 Da salt, widely available without prescription as a dietary supplement that we add to CUSP9 on that basis. This might not be necessary in that it is thought that plain disulfiram rapidly chelates copper after ingestion [96]. The United States' FDA has concluded that copper (cupric) gluconate is a category 1, Generally Regarded as Safe (GRAS) substance. In their words category 1 means that "There is no evidence in the available information on (substance) that demonstrates, or suggests reasonable grounds to suspect, a hazard to the public when they are used at levels that are now current or might reasonably be expected in the future." [156].

\section{II.2.5. nelfinavir.}

Nelfinavir is a $568 \mathrm{Da}$ oral aspartic protease inhibitor in use for over ten years in the treatment of HIV. It is usually well tolerated, short term side effects are few. If gradual up titration is observed, loose stool without need for treatment was the only immediate side effect of note. In HIV-infected persons, years of treatment with HIV protease inhibitors may lead to metabolic disturbances, lipodystrophy, and insulin resistance [157].

HSP90 is a dimeric ATP-binding chaperone protein that binds to and thereby conformationally stabilizes many signaling receptors and crucial intracellular proteins [158]. Many signaling receptors shown to be important in glioblastoma growth are such HSP90 stabilized proteins or protein complexes. Some of these are diagramed in Fig. 5. There are many other client proteins of HSP90 that are of potential importantance in glioblastoma growth. Nelfinavir, like the older, related, $721 \mathrm{Da}$ protease inhibitor ritonavir, binds to and prevents or limits the chaperone function of HSP90 [159-161] with multiple beneficial cancer chemotherapy consequences, some of which are outlined below.

Wide interest in nelfinavir as an effective new anticancer drug [162-165], in particular in the adjuvant role in combination treatment, isreflected by the implementation 
of more than two dozen clinical studies with cancer patients as of the end of 2012 (www.clinicaltrials. gov) that are currently ongoing, including two studies with glioma patients (NCT00915694: nelfinavir plus temozolomide plus radiation; NCT01020292: nelfinavir plus temozolomide).

Increased endoplasmic reticulum (ER) stress [163, 167] and HSP90 function interference [161] are major paths by which nelfinavir is thought to exert an anti-cancer effect. Loci of nelfinavir's undermining of several core survival enhancing paths engaged by temozolomide can be seen diagrammed in Fig. 5.

Nelfinavir-mediated ER stress, probably caused by nelfinavir's inhibition of a yet unidentified ER associated aspartic proteinase involved in protein processing, leads to a massive accumulation of misfolded proteins within the ER lumen, triggering the pro-apoptotic pathway of the ER stress signaling cascade $[163,167,168]$. In glioma cells, nelfinavir-mediated ER stress was shown to up regulate pro-apoptotic proteins and to induce cleavage of caspase 4 in vitro and in a xenograft model [168].

Nelfinavir has not only been shown to be effective against a wide variety of different cancer cell lines at clinically relevant levels [169-171], but more importantly has also been shown to be similarly effective on ex vivo biopsy tissue from patients with primary and recurrent ovarian cancer [163]. This indicates a possible use of nelfinavir for relapsed cancer, independent of previously acquired chemoresistance. Particularly in myeloma cells can impaired proliferation and proteosome inhibition be seen after exposure to nelfinavir, with curiously enhanced inhibition to that provided by the marketed proteosome inhibitor bortezomib [171].

Experimental (not marketed) inhibitors other than nelfinavir or ritonavir e.g., derivatives of geldanamycin like 17-allylamino-17-demethoxygeldanamycin (17AAG), are in active research programs as adjuncts to traditional current cancer cytotoxic chemotherapy. Trials of these drugs are based on strong pre-clinical evidence that HSP90 inhibition undermines several compensatory survival enhancing responses to temozolomide in glioblastoma [172], in other cancers [173] and in gliomas to other cytotoxic chemotherapeutic drugs [174-176].

Specific studies on temozolomide action in glioma have shown HSP90 inhibition (again mostly but not uniquely using 17-AAG) as a strong sensitizing maneuver to glioma cells otherwise resistant to temozolomide [174, 177] or irradiation [178]. Several novel [not marketed] HSP90 inhibitors have shown strong cytotoxicity against glioblastoma specifically against the stem cell subpopulation $[175,176,179,180]$. Empirical inhibition is seen of proliferation of glioblastoma cell lines U251, A172, and U373 during exposure to nelfinavir alone but without significant apoptosis induction [181]. Increased vulnerability in nelfinavir-exposed cells to apoptosis induction by other agents was however demonstrated
[181].

Matrix metalloproteinase-2 (72 kDa, MMP-2, also termed gelatinase A) and MMP-9 (94 kDa, also termed gelatinase B) are proteolytic collagenases strongly associated with glioblastoma growth and invasion [159, 182, 183]. MMP-9 secretion is an HSP90 requiring event [184]. Note that three of CUSP9 drugs inhibit MMP-2, MMP-9- captopril, disulfiram, and nelfinavir, as referenced in the respective sections of this paper, and have previously been suggested as a mutually reinforcing trio of drugs well-suited as mutually reinforcing adjuvants in the treatment of glioblastoma [159].

Phosphatase and tensin homologue (PTEN) is a phosphatase that constitutively inhibits or functions to diminish AKT (protein kinase B, a serine/threonine kinase) signaling. PTEN is often malfunctioning in glioblastoma, resulting in AKT related constitutive overdrive. AKT is one of the many intracellular proteins requiring HSP90 chaperoning for optimal functioning. Experimental HSP90 inhibitors like 17-AAG [177] as well as nelfinavir and ritonavir inhibit AKT function [161, 185-190], partially reversing faulty PTEN function as commonly seen in, and forming one of the core growth enhancing abnormalities of, glioblastoma [191-193]. In 2006 Pore et al. showed decreased VEGF, hypoxia induced factor-1 (HIF-1), and AKT activation in U87 glioma cells and decreased angiogenesis into U87 seeded, subcutaneously placed Matrigel plugs in mice treated with oral nelfinavir [194, 195].

We therefore expect some of the growth drive consequent to PTEN loss common in glioblastoma [193] resulting overactivation of $\mathrm{AKT}$ to be partially reversed by nelfinavir.

Of the many proteins that use HSP90 for correct folding and function, one of the most important in glioblastoma pathophysiology is perhaps transforming growth factor-beta (TGF-beta) [196-199]. That TGF-beta sits at a crucial crossroads in glioblastoma's dysregulation as recently reviewed by Eyler and Rich makes HSP90 a particularly attractive target [30]. This crossroads position of HSP90 in this regard is also indicated in Fig. 5.

Benefit was clear when nelfinavir was added to standard chemoradiation in a recent study of unresectable non-small cell lung cancer [200]. Of particular note was that this benefit was achieved using the dose we suggest for CUSP9, $1250 \mathrm{mg}$ p.o. twice daily, and that this gave little evidence of added side effect burden to patients [200].

A remarkable research of Xie et al. showed that "nelfinavir is able to inhibit multiple members of the protein kinase-like superfamily" in addition to lowering AKT activation. Perhaps most interesting of all was their observation and their accompanying conceptual leap, that weak inhibition of multiple growth enhancing kinases as provided by nelfinavir can result in significant anti-cancer activity, not necessarily by itself but by setting up the 
intracellular milieu to be less robust in coping with other insults like irradiation or traditional cytotoxic drugs [190], or in our case nelfinavir undermining survival paths that are engaged after exposure to temozolomide.

We expect nelfinavir to be well tolerated. In HIV studies only about $4 \%$ of nelfinavir treated patients switched to other drugs due to side effects [201] and in a recently reported clinical study of nelfinavir as cancer treatment adjuvant nelfinavir added little morbidity [200].

For treatment of HIV-infected persons, nelfinavir is more and more being replaced by ritonavir-boosted HIV protease inhibitors of the newer generation. Some of these HIV protease inhibitors, including lopinavir, atazanavir [168], and even ritonavir as a single agent [185,189, 202], have been shown to have similar anti-tumoral (but this does not imply identical) effects as nelfinavir. Since nelfinavir is the currently most investigated HIV drug for cancer treatment, this treatment plan will focus on the incorporation of nelfinavir but remains open for the inclusion or replacement by other HIV protease inhibitors in case that preclinical or clinical data indicate a superiority of other marketed HIV protease inhibitors in glioblastoma treatment.

\section{II.3. Published reports of increased OS with use but of uncertain significance and drugs with less robust theoretical support- captopril, sertraline, ketoconazole}

\section{II.3.1. sertraline}

Sertraline is a $306 \mathrm{Da}$ selective serotonin re-uptake inhibitor (SSRI) in common use over the last twenty years in the treatment of depressed mood [203]. It is usually well-tolerated and is effective in about half of patients started on it [203, 204].

By formal study of glioblastoma patients, an $18 \%$ rate of moderate to severe depression is seen postresection [205] but other studies would suggest that the actual rate of depression-related signs and symptoms was considerably higher and that these significantly degraded quality of life in glioblastoma patients [206]. Family member interviews indicate that glioblastoma patients experience greater depression signs than the patients themselves report [207].

A recent study of 1,364 glioma patients showed a non-significant longer survival ["suggestive trend towards a beneficial association"] in those treated post-diagnosis with tricyclic antidepressants [208]. Not only don't we know if this data is a real effect or not (potential for propter hoc fallacy) but also we don't know that, if it were a real association (longer survival if treated with a tricyclic antidepressant) would this carry over to the modern SSRI's generally or sertraline specifically. However Caudill et al. at the Mayo Clinic reported also a non-significant longer survival in glioblastoma patients on an SSRI class antidepressant such as sertraline compared to those not on such..."Two-year survival in the cohort of patients taking an SSRI was $32 \%$ versus $17 \%$ in those who were not $(\mathrm{P}=$ 0.18)." [ 209]. No excess toxicity was noted in the SSRI treated patients [ 209].

Additive anti-proliferative effect in U87 glioblastoma cells was seen with temozolomide plus sertraline in vitro [210]. Down regulation of AKT with some reduced proliferation was seen in melanoma cells exposed to sertraline [211] but it was undetermined if this was related to serotonin reuptake inhibition or some other attribute of sertraline. So all above considerations taken together we consider the minimal risks of adding sertraline to be worth any gains that might accrue, were this data, particularly of slight increases in OS, to hold.

\section{II.3.2. captopril}

Angiotensin conversion enzyme inhibitors (ACEI) are a class of eminently well-tolerated drugs commonly used to treat hypertension, or congestive heart failure [212, 213]. ACEI inhibit the proteolytic cleavage of angiotensin I to angiotensin II. A related class of drugs, sartans, binds to and prevents the stimulation of the angiotensin II receptor.

In a study of 87 glioblastoma patients, those on ACEI or a sartan had lower need for dexamethasone [214]. This steroid-sparing use of ACEI alone holds potential to improve QOL, in that psychiatric $[215,216]$, metabolic [217], and immunosuppressive [218] morbidities secondary to dexamethasone use in glioblastoma are not trivial. The Carpentier et al. study's finding of a nonsignificant increase in OS in the ACE inhibited group was intriguing [ACEI use had "no effect on survival (16.2 vs. 17.9 months for the treated and the non-treated group, respectively, $\mathrm{P}=0.77$ )"] [214]. Data like this not meeting statistical significance, as with the non-significant increase in OS noted in Caudil et al.'s study of SSRIs, can both a) be a real, important, and ultimately statistically significant difference that becomes evident on further study with larger populations, and b) allow important insights into pathophysiology of a given disease if the difference proves to be statistically significant even if not clinically meaningful to patients in itself.

Captopril is a $217 \mathrm{Da}$ oral ACEI, the first such to enter clinical use [219]. Since then many other ACEI's have been approved yet captopril remains useful in treating hypertension and as remodeling inhibitor post-myocardial infarction [219]. Although hypotension is a theoretical risk, captopril has a history of safe use in uncomplicated hypertension. Orthostatic hypotension incidence remains low even in setting of captopril use in congestive failure and post-myocardial infarction [220].

In experimental systems, the antitumor effects of diverse ACE inhibitors and sartans show that as a class they inhibit cell proliferation and possess antiangiogenic, antimetastatic effects in multiple cancer models; 
hepatocellular [221], squamous cell [222], renal cell [222224], gliomas [225, 226], bladder [227], ovarian [228], prostate [229], breast [230], colon [231], gastric [232]. On this basis as well we feel the ACEI effect of Carpentier et al. will prove to be validated as a slight but statistically significant benefit when greater numbers are studied.

Human glioblastoma cells express immunohistochemistry demonstrable renin and angiotensinogen mRNAs and proteins, as well as renin and angiotensin 1 or 2 receptors [233]. Fully $67 \%$ of human glioblastomas expressed angiotensin 1 receptors, $53 \%$ expressed angiotensin 2 receptors [225].

Losartan, a sartan class pharmaceutical angiotensin II receptor blocker, reduced the growth of C6 glioma in rats [234]. Glioma cell line T98G constitutively synthesizes MMP-2 and MMP-9. This is inhibited by captopril with an expected consequent inhibition of Matrigel invasion inhibition [235]. As human glioblastoma tissue produces prodigious amounts of both MMP-2 and MMP-9, collagenases strongly associated with glioblastoma growth and invasion [159, 182, 183] captopril was previously mentioned as an obvious therapeutic intervention for glioblastoma [159].

\section{II.3.3. ketoconazole.}

Ketoconazole is a $531 \mathrm{Da}$ broad spectrum antifungal drug, used in both topical and oral applications [236]. Several paths of importance in glioblastoma growth have good experimental documentation of inhibition by ketoconazole. To what extent ketoconazole congeners like miconazole or fluconazole share the discussed properties of ketoconazole is likewise unknown. Fluconazole penetration into brain tissue approaches 1:1 with blood levels but it might not possess the four attributes of ketoconazole outlined below.

Ketoconazole is a potent inhibitor of a) 5lipoxygenase [237- 239], b) thromboxane synthase [240243], c) a drug efflux pump at the blood-brain barrier [244- 250], and d) has shown an empirical inhibition of cancer cell growth $[238,239]$.

In a study of long-term ketoconazole treatment of onychomycosis, $18 \%$ of people developed slight liver transaminase elevation, 3\% developed transaminase elevations high enough to trigger stopping ketoconazole [251]. Reviews on the risks/benefits of ketoconazole and related anti-fungal drugs have concluded risks for ketoconazole use are low [252]. A total of about ten case studies have been published of fatal hepatitis during oral ketoconazole treatment [253].

In advanced prostate cancer patients on docetaxel given adjunctive ketoconazole at $200 \mathrm{mg}$ p.o. three times daily this was well-tolerated, giving $1.24 \mathrm{microg} / \mathrm{mL}$ trough and $2.79 \mathrm{microg} / \mathrm{mL}$ peak plasma ketoconazole levels during steady-state [254]. a) Ketoconazole \& 5-lipoxygenase:

Arachidonate 5-lipoxygenase (arachidonate:oxygen 5-oxidoreductase, EC 1.13.11.34) is the rate-limiting enzyme in leukotriene synthesis. A proliferation enhancing role in glioblastoma for 5-lipoxygenase generated leukotrienes was first suggested in 1998 when inhibition of 5-lipoxygenase was shown to inhibit proliferation in U-373 glioma cell line [255]. dl-nordihydroguaiaretic acid ("Nordy") is a phytoderived 5-lipoxygenase inhibitor active in inhibiting CD133+ related clonogenicity of glioma cell lines [256]. Glioblastoma biopsy material studied by immunohistochemistry for 5-lipoxygenase shows heavy staining [257]. Two experimental 5-lipoxygenase inhibitors inhibited proliferation of the A172 glioma cell line [257], results confirmed and extended a year later by a different group [258]. A heavy granular staining for 5-lipoxygenase is seen in glioblastoma [and grade 3 astrocytomas] not seen in the even staining of normal neurons and glia [259].

Much of the peritumoral edema seen during glioblastoma is generated by 5-lipoxygenase mediated leukotriene synthesis [260-262]. Human glioblastomas are prodigious producers of leukotrienes [263] the consequence from which derives many of the decrements in QOL and increases in tumor growth vigor. Glioblastoma patients' urinary leukotriene excretion decreases by $79 \%$ post-resection [263] indicating that it was the tumor itself that was generating excess leukotrienes. Exposure to experimental 5-lipoxygenase inhibitors inhibited in vitro glioma cell growth [264, 265]. Increased 5-lipoxygenase in glioblastoma was first noted in 2003 [266], then confirmed in a 2006 immunohistochemistry study showing staining for 5-lipoxygenase where heavier staining correlated with shorter OS [267]. The immunochemistry study of Ishii in 2009 again confirmed this and furthermore showed that experimental 5-lipoxygenase inhibitors inhibit proliferation of A172 glioblastoma cell line [257].

Already in 1989 increased leukotrienes in areas of glioblastoma peritumoral edema were documented [262]. On this basis we can expect diminished peritumoral edema with consequently increased QOL in ketoconazole treated glioblastoma patients as well as, if the data of Ishii et al. and the other indices of anti-glioblastoma effects mentioned hold, longer OS.

\section{b) Ketoconazole \& thromboxane synthase:}

Robust thromboxane A2 content of, and synthetic ability by, human glioblastomas was shown as early as 1987 [268]. Thromboxane A2 receptors are widely expressed on normal tissues and on various cancers, including human glioblastoma cells [269- 271]. Thromboxane synthase catalyzes the formation of thromboxane $\mathrm{A} 2$ from prostaglandin $\mathrm{H} 2$.

Already in 1998, unregulated gene expression with corresponding increase in mRNA for thromboxane 
synthase was noted in glioblastoma cells selected in vitro for enhanced migration [272]. An experimental thromboxane synthase inhibitor [(furegrelate) inhibited glioblastoma cell line growth in vitro and growing in nude mice and most importantly sensitized these cells to he alikylating chemotherapy drug BCNU [273]. This confirmed and extended earlier work showing that thromboxane synthase inhibition diminished in vitro migration and sensitized glioblastoma cell lines to killing by irradiation [274].

Following documentation of increased thromboxane synthase gene and protein expression in the sub-set of glioblastoma cells with a more migratory phenotype compared to the slower moving majority population [277] an in vitro study of exposure to the experimental thromboxane synthase inhibitor furegrelate resulted in caspase activation, DNA fragmentation, and apoptotic death [275].

Thromboxane synthase as a growth facilitating element also in many non-glioma cancers- and the beneficial potential benefit from its inhibition- is an active area of current research [276]. We intend to use the thromboxane synthase inhibitor we already have on the market- ketoconazole.

\section{c) Ketoconazole as efflux pump inhibitor:}

Volume sensitive osmolyte efflux was blocked by ketoconazole [244].

P-glycoprotein efflux of docetaxel at blood brain barrier was inhibited by ketoconazole [245]. We have evidence for ketoconazole inhibiting $\mathrm{BBB}$ efflux of phenobarbital [246] and ritonavir [160, 248]. Ketoconazole inhibits the human breast cancer resistance protein (BCRP) [250], and P-glycoprotein efflux pump [247-249]. Its occasional use in psychiatric practice is based on a) the salutary consequence of ketoconazole's blunting high cortisol excursions [277] and b) increase in brain tissue of certain psychotropic medicines by virtue of its efflux pump inhibition [278].

\section{CUSP9 PHARMACOLOGY:}

\section{IV.1. Introduction.}

The introduction of a therapy with ten-drugs requires a special assessment of safety to limit the risk of adverse drug reactions. The greater the number of drugs, the closer should be the monitoring. We judge a minimum of twice weekly un-hurried meetings with gradual oneby-one addition of drugs and slow up titration will be best for safety. Drug-drug interactions represent a common event and these should be prevented with an adequate protocol of dosing that requires an early assessment of potential interplays between the scheduled medicines. To assess potential interactions each drug of CUSP9 was combined to the others as shown in the grid of Fig. 3. Each pair of drugs was evaluated for the available evidence of interactions using as source of information the Risk Control Plans (RCP) of the reference medicinal product [279], and by a specific research using MEDLINE and Embase.

\section{IV.2. Pharmacokinetic interactions:}

The literature review has provided the evidence that four potential pharmacokinetic interactions may occur for the group of drugs scheduled in the protocol: ketoconazole + aprepitant, nelfinavir + aprepitant, artesunate + ketoconazole and artesunate + nelfinavir.

IV.2.1. Ketoconazole + aprepitant and nelfinavir + aprepitant

CYP3A4 is the major enzyme involved in the metabolism of aprepitant [280]. Ketoconazole is wellknown as one of the most potent inhibitors known of CYP3A4. In vitro studies showed that ketoconazole may inhibit the $98 \%$ of aprepitant metabolism, with a marked increase in its bioavailability (5-fold increase of AUC, 3 -fold increase of half-life) [280, 281]. Nelfinavir inhibits CYP3A4 [282, 283]. No study has directly tested the effect of nelfinavir on aprepitant levels or metabolism. It is therefore difficult to quantify the pharmacokinetic result of this potential interaction. In terms of clinical relevance, if used in standard doses, the combination ketoconazolenelfinavir-aprepitant may result in very high levels of aprepitant. In the previously mentioned antidepressant article $300 \mathrm{mg}$. aprepitant per day (twice the dose suggested for CUSP9) gave no side effects different from placebo $[36,49]$.

\section{IV.2.2. Ketoconazole + artesunate and nelfinavir + artesunate}

As mentioned above, ketoconazole and nelfinavir are both potent inhibitors of CYP3A4. CYP3A4 is also involved in the metabolism of artesunate [284]. Nelfinavir and ketoconazole can be expected to increase artesunate levels. As a consequence, the possibility of artesunate dose-related adverse reactions is enhanced, among which the most relevant would be QT prolongation [285]. A QTc of $>0.42$ will exclude artesunate from CUSP9.

\section{IV.3. Pharmacodynamic interactions}

The literature review did not provide direct evidence of specific pharmacodynamic interaction among the drugs included in the protocol. However, considering the main categories of adverse drug reaction for each drug, a potential hepatotoxic effect is expected for ketoconazole [286], nelfinavir [287] and temozolomide [288]. Patients exposed to the combination of these three drugs should be monitored by at least monthly assessments of liver 
functions.

A further potential pharmacodynamic interaction would be that between auranofin and artesunate. The use of artesunate is contraindicated in patients receiving aurothioglucose since both drugs have been associated with the development of blood dyscrasias [289]. Although a specific contraindication with auranofin is not reported, we should expect risk for similar interaction with auranofin + artesunate, warranting frequent blood counts when these are given.

\section{IV.4. Felicitous drug-drug interactions:}

IV.4. 1. Protection against artesunate cytotoxicity is afforded by intracellular ROS reducing agents [58-60], important elements of which of which are inhibited by auranofin $[81,82]$ and disulfiram $[100,117,152]$.

IV.4. 2. Auranofin does double duty. First as thioredoxin reductase inhibitor $[290,291]$ then as cathepsin B inhibitor [79, 80, 84, 94].

IV.4. 3. Note that three CUSP9 drugs inhibit MMP-2 \& MMP-9- captopril, disulfiram, and nelfinavir [159, 292]

IV.4. 4.Two drugs of CUSP9 have inhibitory activity at relevant drug efflux pumps, disulfiram [108, 109, 139], and ketoconazole [245-250].

IV.4. 5. Both disulfiram $[98,100,121-124]$ and nelfinavir and other HSP90 inhibitors [294- 296] have shown specificity in inhibiting cancer stem cell function.

IV.4. 6. Both artesunate [297] and nelfinavir [194, 195] lower both VEGF and HIF-1 activity.

IV.4. 7. Interference with AKT function has been noted after exposure to sertraline [211] and nelfinavir [55, $65]$.

IV.4.8. Disulfiram and ritonavir acting together inhibit ICE-1, lowering IL-1 beta growth drive to glioblastomas [153, 154], also diagramed in Fig. 4.

\section{RISK REDUCTION, RISK ASSESSMENT, AND PARTIAL CUSP'S.}

\section{V.1. Safety features built into CUSP9.}

Underpinning the entire CUSP9 treatment process and a crucial component of CUSP9 are the safety features that must be in place for a new many-drug protocol like this. Sudden onset drug-drug interactions can usually be prevented by considering, as we have done, researching literature and history of drugs under consideration and their individual pharmacologic attributes. Specific safety requirements of CUSP9 are therefore:

\section{V.1.1 Frequent meetings.}

Onset of drug-drug interactions is usually gradual. Early recognition of a negative interaction is enhanced by slow up titration. Unhurried careful weekly meetings are required for CUSP9 to function safely. We will have better chances to catch incipient unexpected interactions quickly this way.

\section{V.1.2. Addition of one drug at a time.}

To minimize unforeseen drug-drug interactions with a complicated but necessary regime like CUSP9, a single drug only is added at each meeting. The next drug is added only when it has been established that that latest added drug has not generated a problem. The one exception to this rule will be copper gluconate that will be given with each disulfiram or not given if disulfiram is not tolerated.

\section{V.1.3. Slow up titration.}

Drugs will be added at the low end of their dose range and slowly up titrated if meeting with the patient, and lab study if needed, establish that the last dose has been well tolerated.

\section{V.1.4. Frequent lab monitoring.}

Weekly check of EKG, liver, kidney, and bone marrow function will be a minimum.

V.1.5.

Patients will have a 24 hour phone contact with their monitoring physician and instructions to call if there is any deterioration in any domain.

\section{V.1.6. Exclusions.}

A lengthy and detailed exclusion criteria list will help safety. Among many other exclusions, herbal preparations, nutritional supplements, or over-the-counter medicines or other ancillary medicines will not be allowed with 3 exceptions: 1) Hypertension controlled on any combination of ACEI or sartans will be permitted, in which case captopril is omitted from CUSP9, and 2) noninsulin requiring diabetes well controlled on metformin will be allowed. The use of grapefruit juice or extracts will be discouraged because of its CYP3A4 inhibiting effect. 3) Hydromorphone will be allowed for pain control.

\section{V.1.7. Partial CUSP's.}

If an untoward reaction or side effect is seen with the addition of a particular drug, that drug will be dropped from that patient's treatment protocol and the addition process will continue as planned minus that drug, after restitution to the state of well-being established prior to addition of the offending drug. No further additions will be given if such restitution does not occur.

\section{V.2. Our safety assessment.}

Using our clinical experience with these drugs combined with published data, to help others understand the safety structure better we have stratified the relative risk of the ten drugs as temozolomide >auranofin $>$ 
ketoconazole $>$ nelfinavir $>$ artesunate $>$ sertraline $>$ captopril $>$ disulfiram $>$ aprepitant $>$ copper gluconate.

For heuristic reasons and as options for patients and physicians who are timorous we offer a suggestion to consider partial CUSP's in four risk category combinations.

\section{V.2.1. Low risk combination:}

Given at the low end of our target dosing range, aprepitant $80 \mathrm{mg}$ twice daily, sertraline $50 \mathrm{mg}$ twice daily, captopril $25 \mathrm{mg}$ twice daily, disulfiram $250 \mathrm{mg}$ twice daily, copper gluconate $2 \mathrm{mg}$ twice daily.

\section{V.2.2. Medium risk combination:}

artesunate or auranofin, nelfinavir, ketoconazole in addition to the low risk drug combination.

\section{V.2.3. Higher risk combination:}

temozolomide, combination auranofin and artesunate in addition to drugs of the low and medium group, the full CUSP9 given at our suggested target doses:

1....artesunate $50 \mathrm{mg}$ p.o. twice daily

2....aprepitant $80 \mathrm{mg}$ p.o. twice daily

3....sertraline $50 \mathrm{mg}$ p.o. twice daily

4....captopril $50 \mathrm{mg}$ p.o. twice daily

5....auranofin $3 \mathrm{mg}$ p.o. twice daily

6....nelfinavir $1250 \mathrm{mg}$ p.o. twice daily

7 ....temozolomide $25 \mathrm{mg} / \mathrm{M}^{2}$ p.o. twice daily

8....disulfiram $250 \mathrm{mg}$ p.o. twice daily

9....copper (cupric) gluconate $2 \mathrm{mg}$ p.o. twice daily 10 ...ketoconazole $200 \mathrm{mg}$ p.o. twice daily

\section{A CUSP9 SUMMARY:}

The use of old drugs for new indications, coined "repurposing" is a realistic concept to accelerate therapy development for many cancers, previously formulated by many others [for example 25, 113, 120, 299, 300]. We herein add our voice and suggest a specific, coordinated old drug mix- CUSP9- as a multipronged coordinated attempt to augment current treatment of recurrent glioblastoma. In parallel with bacteriology practice we believe that a combination strategy such as CUSP9 is less likely to allow development of chemotherapeutic resistance as usually occurs in cancer treatment and specifically limits clinical efficacy of temozolomide in glioblastoma.

We, The International Initiative for Accelerated Improvement of Glioblastoma Care, heartily invite suggestions, comments, or proposals for additions or deletions, or further improvement of the CUSP9 protocol, or its translational use in other cancer treatments. Indeed allowing wide debate, critical thinking, and feedback with intent to improve CUSP9 was a central motive for publishing this protocol. Comments to either of the corresponding authors will be sent to all co-authors for discussion and evaluation.
We are not the first (nor was Virchow when he discussed this in mid-1800's) to suggest a connection between inflammation pathways and cancer, and to consider blocking these as a cancer treatment modality [301-305]. The term "inflammation" is too imprecise to be useful in discussing the relationship between the malignant clone/cells and the rest of the body [301, 302]. CUSP9 aims to inhibit elements of inflammation that enhance glioblastoma growth.

There are many open questions. To what degree do nelfinavir and ritonavir share attributes? To what degree does ketoconazole increase CSF levels of nelfinavir as it does for ritonavir? Will BBB opening maneuvers be required for any of the CUSP9 drugs? Will any of the drugs work against any of the others in ways we don't foresee? To what extent are associations with angiotensin inhibition and longer OS, or SSRI use and longer OS, simple propter hoc fallacies or real meaningful or causal elements?

Two of our CUSP9 drugs- disulfiram and ritonavir/ nelfinavir have a potential synergy in inhibiting a growth path used in glioblastoma that resembles closely an IL1 beta converting enzyme (ICE-1, also termed caspase-1) and IL-18 mediated inflammation paths in some cases of acute pancreatitis [153], diagramed in Fig. 4. "Reducing IL-1beta and IL-18 production by inhibition of ICE-1 is one promising strategy..." [303] in cancer treatment [294, 301- 303, 306] that was outlined already in 2001 by Randle's group in München. IL-18 and IL-1beta are both well documented growth facilitating elements in glioblastoma [306, 307]. We take up this thread by using disulfiram and nelfinavir to do exactly that- ICE inhibition with disulfiram and nelfinavir to inhibit IL-1 and IL18 activation, details of which are pharmacologically explained in ref. 153 and depicted in Fig.4. We intend to thereby re-re-wire the pathogenically re-wired, amplifying feedback loop between HIF-1 and IL-1 common in cancers generally as described by Kaluz and Van Meir [307].

Aspects of our approach are similar to that being implimented in pediatric glioblastoma by J. Wolff et al. [308] at Tufts University where relapse post-primary treatment is selected in part by morphometric and immunohistochemical data that show which markers an individual tumor bears, then searching for alreadymarketed drugs that may block that receptor system or marker. This can lead to use of non-cytotoxic drugs not traditionally thought of as cancer chemotherapeutic drugsas in CUSP9.

As referenced throughout our paper, CUSP9 is weighted towards interference with glioblastoma stem cell function, a particularly fruitful sub-population to target, offering higher reward yet having similar risks as targeting the tumor cell population as a whole [309, 310]. Glioblastoma stem cells have a complex interaction with their surrounding brain parenchyma, stroma and extracellular matrix [311]. There is a bidirectional 
relationship between these two compartements (surrounding brain and the glioblastoma cell) [311, 312] with which CUSP9 aims to block, as discussed throught this paper.

Both that $>99 \%$ of patients will experience progression post-primary treatment and the short median OS of patients with glioblastoma warrant taking the measured and manageable risks of CUSP9. The 22 reports of failed studies of new treatments using variations on traditional cancer therapeutic published in 2012 [1, 3-23] also justify our excursion into conceptually new treatment approaches as here in CUSP9. CUSP9 complexity and requirement for large clinician time commitment per treated patient may be unavoidable if we are to make a dent in this tough disease.

So as in Preamble- ecce turtur. ipse proficit tantum con collum foras.

\section{CONFLICTS OF INTEREST:}

Miguel Muñoz: U.S. Patent Trademark Office Application no. 20090012086: Use of nonpeptidic NK-1 receptor antagonists for the production of apoptosis in tumor cells. None of the other 27 authors have any conflict of interest.

\section{REFERENCES}

1. Stummer W, Meinel T, Ewelt C, Martus P, Jakobs O, Felsberg J, Reifenberger G. Prospective cohort study of radiotherapy with concomitant and adjuvant temozolomide chemotherapy for glioblastoma patients with no or minimal residual enhancing tumor load after surgery.J Neurooncol. 2012;108:89-97. doi: 10.1007/s11060-012-0798-3.

2. Dressmann G. Temozolomide in malignant glioma. Onco Targets Ther. 2010;3:139-46. PubMed PMID: 20856849; PMCID:PMC2939767.

3. Chinnaiyan P, Chowdhary S, Potthast L, Prabhu A, Tsai YY, Sarcar B, Kahali S, Brem S, Yu HM, Rojiani A, Murtagh R, Pan E. Phase I trial of vorinostat combined with bevacizumab and CPT-11 in recurrent glioblastoma. Neuro Oncol. 2012;14:93-100. doi: 10.1093/neuonc/nor187.

4. Conti A, Pontoriero A, Arpa D, Siragusa C, Tomasello C, Romanelli P, Cardali S, Granata F, De Renzis C, Tomasello F. Efficacy and toxicity of CyberKnife re-irradiation and "dose dense" temozolomide for recurrent gliomas. Acta Neurochir (Wien). 2012;154:203-9. doi: 10.1007/s00701011-1184-1.

5. Desjardins A, Reardon DA, Coan A, Marcello J, Herndon JE 2nd, Bailey L, Peters KB, Friedman HS, Vredenburgh JJ. Bevacizumab and daily temozolomide for recurrent glioblastoma. Cancer. 2012;118:1302-12. doi:10.1002/ cncr.26381.

6. Franceschi E, Stupp R, van den Bent MJ, van Herpen C, Laigle Donadey F, Gorlia T, Hegi M, Lhermitte B, Strauss
LC, Allgeier A, Lacombe D, Brandes AA EORTC 26083 phase I/II trial of dasatinib in combination with CCNU in patients with recurrent glioblastoma. Neuro Oncol. 2012;14:1503-10. doi: 10.1093/neuonc/nos256.

7. Friday BB, Anderson SK, Buckner J, Yu C, Giannini C, Geoffroy F, Schwerkoske J, Mazurczak M, Gross H, Pajon E, Jaeckle K, Galanis E. Phase II trial of vorinostat in combination with bortezomib in recurrent glioblastoma: a north central cancer treatment group study. Neuro Oncol. 2012;14:215-21. doi:10.1093/neuonc/nor198.

8. Gil MJ, de Las Peñas R, Reynés G, Balañá C, PerézSegura P, García-Velasco A, Mesia C, Gallego O, Fernández-Chacón C, Martínez-García M, Herrero A, Andrés R, Benavides M, Quintanar T, Pérez-Martin X. Bevacizumab plus irinotecan in recurrent malignant glioma shows high overall survival in a multicenter retrospective pooled series of the Spanish Neuro-Oncology Research Group. Anticancer Drugs. 2012;23:659-65. doi:10.1097/ CAD.0b013e3283534d3e.

9. Gilbert MR, Kuhn J, Lamborn KR, Lieberman F, Wen PY, Mehta M, Cloughesy T, Lassman AB, Deangelis LM, Chang S, Prados M. Cilengitide in patients with recurrent glioblastoma: the results of NABTC 03-02, a phase II trial with measures of treatment delivery. J Neurooncol. 2012;106:147-53. doi: 10.1007/s11060-011-0650-1.

10. Giglio P, Dhamne M, Hess KR, Gilbert MR, Groves MD, Levin VA, Kang SL, Ictech SE, Liu V, Colman H, Conrad CA, Loghin M, de Groot J, Yung WK, Puduvalli VK. Phase 2 trial of irinotecan and thalidomide in adults with recurrent anaplastic glioma. Cancer. 2012;118:3599-606. doi: 10.1002/cncr.26663.

11. Lv S, Teugels E, Sadones J, De Brakeleer S, Duerinck J, Du Four S, Michotte A, De Grève J, Neyns B. Correlation of EGFR, IDH1 and PTEN status with the outcome of patients with recurrent glioblastoma treated in a phase II clinical trial with the EGFR-blocking monoclonal antibody cetuximab. Int J Oncol. 2012;41:1029-35. doi: 10.3892/ ijo.2012.1539.

12. Mason WP, Belanger K, Nicholas G, Vallières I, Mathieu D, Kavan P, Desjardins A, Omuro A, Reymond D. A phase II study of the Ras-MAPK signaling pathway inhibitor TLN-4601 in patients with glioblastoma at first progression. J Neurooncol. 2012;107:343-9. doi: 10.1007/s11060-0110747-6.

13. McPherson CM, Gerena-Lewis M, Breneman JC, Warnick RE. Results of phase I study of a multi-modality treatment for newly diagnosed glioblastoma multiforme using local implantation of concurrent BCNU wafers and permanent I-125 seeds followed by fractionated radiation and temozolomide chemotherapy. J Neurooncol. 2012;108:5215. doi: 10.1007/s11060-012-0854-z.

14. Møller S, Grunnet K, Hansen S, Schultz H, Holmberg M, Sorensen M, Poulsen HS, Lassen U. A phase II trial with bevacizumab and irinotecan for patients with primary brain tumors and progression after standard therapy. Acta Oncol. 
2012;51:797-804. doi: 10.3109/0284186X.2012.681063.

15. Nagane M, Nishikawa R, Narita Y, Kobayashi H, Takano S, Shinoura N, Aoki T, Sugiyama K, Kuratsu J, Muragaki Y, Sawamura Y, Matsutani M. Phase II study of single-agent bevacizumab in Japanese patients with recurrent malignant glioma. Jpn J Clin Oncol. 2012;42:887-95.

16. Oehler C, Frei K, Rushing EJ, McSheehy PM, Weber D, Allegrini PR, Weniger D, Lütolf UM, Knuth A, Yonekawa Y, Barath K, Broggini-Tenzer A, Pruschy M, Hofer S. Patupilone (epothilone B) for recurrent glioblastoma: clinical outcome and translational analysis of a singleinstitution phase I/II trial. Oncology. 2012;83:1-9. doi: $10.1159 / 000339152$.

17. Paccapelo A, Lolli I, Fabrini MG, Silvano G, Detti B, Perrone F, Savio G, Santoni M, Bonizzoni E, Perrone T, Scoccianti S. A retrospective pooled analysis of response patterns and risk factors in recurrent malignant glioma patients receiving a nitrosourea-based chemotherapy. J Transl Med. 2012;10:90. doi:10.1186/1479-5876-10-90.

18. Rampling R, Sanson M, Gorlia T, Lacombe D, Lai C, Gharib M, Taal W, Stoffregen C, Decker R, van den Bent MJ. A phase I study of LY317615 (enzastaurin) and temozolomide in patients with gliomas (EORTC trial 26054). Neuro Oncol. 2012;14:344-50. doi: 10.1093/ neuonc/nor221.

19. Reardon DA, Conrad CA, Cloughesy T, Prados MD, Friedman HS, Aldape KD, Mischel P, Xia J, DiLea C, Huang J, Mietlowski W, Dugan M, Chen W, Yung WK. Phase I study of EE788, a novel multitarget inhibitor of ErbB- and VEGF-receptor-family tyrosine kinases, in recurrent glioblastoma patients. Cancer Chemother Pharmacol. 2012;69:1507-18. doi: 10.1007/s00280-0121854-6.

20. Reardon DA, Desjardins A, Peters KB, Gururangan S, Sampson JH, McLendon RE, Herndon JE 2nd, Bulusu A, Threatt S, Friedman AH, Vredenburgh JJ, Friedman HS. Phase II study of carboplatin, irinotecan, and bevacizumab for bevacizumab naïve, recurrent glioblastoma. J Neurooncol. 2012;107:155-64. doi: 10.1007/s11060-0110722-2.

21. Sorensen AG, Emblem KE, Polaskova P, Jennings D, Kim $\mathrm{H}$, Ancukiewicz M, Wang M, Wen PY, Ivy P, Batchelor TT, Jain RK. Increased survival of glioblastoma patients who respond to antiangiogenic therapy with elevated blood perfusion. Cancer Res. 2012;72:402-7. doi: 10.1158/00085472.CAN-11-2464.

22. Stupp R, Wong ET, Kanner AA, Steinberg D, Engelhard H, Heidecke V, Kirson ED, Taillibert S, Liebermann F, Dbalý V, Ram Z, Villano JL, Rainov N, Weinberg U, Schiff D, Kunschner L, Raizer J, Honnorat J, Sloan A, Malkin M, Landolfi JC, Payer F, Mehdorn M, Weil RJ, Pannullo SC, Westphal M, Smrcka M, Chin L, Kostron H, Hofer S, Bruce J, Cosgrove R, Paleologous N, Palti Y, Gutin PH. NovoTTF-100A versus physician's choice chemotherapy in recurrent glioblastoma: a randomized phase III trial of a novel treatment modality. Eur J Cancer. 2012;48:2192-202. doi: 10.1016/j.ejca.2012.04.011.

23. White E, Bienemann A, Taylor H, Hopkins K, Cameron A, Gill S. A phase I trial of carboplatin administered by convection-enhanced delivery to patients with recurrent/ progressive glioblastoma multiforme. Contemp Clin Trials. 2012;33:320-31. doi: 10.1016/j.cct.2011.10.010.

24. Dörner L, Mustafa A, Rohr A, Mehdorn HM, Nabavi A. Growth pattern of tumor recurrence following bischloroethylnitrosourea (BCNU) wafer implantation in malignant glioma. J Clin Neurosci. 2013 Jan 10. doi:pii: S0967-5868(12)00440-7. 10.1016/j.jocn.2012.01.060. [Epub ahead of print] PubMed PMID: 23313517.

25. Kast RE. Profound blockage of CXCR4 signaling at multiple points using the synergy between plerixafor, mirtazapine, and clotrimazole as a new glioblastoma treatment adjunct. Turk Neurosurg. 2010;20:425-9. doi: 10.5137/1019-5149.JTN.3334-10.0.

26. Thirant C, Gavard J, Junier MP, Chneiweiss H. Critical multiple angiogenic factors secreted by glioblastoma stem-like cells underline the need for combinatorial antiangiogenic therapeutic strategies. Proteomics Clin Appl. 2013;7(1-2):79-90. doi: 10.1002/prca.201200102.

27. Guo J, Niu R, Huang W, Zhou M, Shi J, Zhang L, Liao $H$. Growth factors from tumor microenvironment possibly promote the proliferation of glioblastoma-derived stem-like cells in vitro. Pathol Oncol Res. 2012;18:1047-57. PubMed PMID: 22996727.

28. Yang L, Lin C, Wang L, Guo H, Wang X. Hypoxia and hypoxia-inducible factors in glioblastoma multiforme progression and therapeutic implications. Exp Cell Res. 2012;318:2417-26. doi: 10.1016/j.yexcr.2012.07.017.

29. Siegelin MD, Plescia J, Raskett CM, Gilbert CA, Ross AH, Altieri DC. Global targeting of subcellular heat shock protein-90 networks for therapy of glioblastoma. Mol Cancer Ther. 2010;9:1638-46. doi:10.1158/1535-7163. MCT-10-0097.

30. Eyler CE, Rich JN.Looking in the miR-ror: TGF- $\beta$ mediated activation of $\mathrm{NF}-\kappa \mathrm{B}$ in glioma. J Clin Invest. 2012;122:3473-5. doi: 10.1172/JCI66058.

31. Reddy K, Damek D, Gaspar LE, Ney D, Waziri A, Lillehei K, Stuhr K, Kavanagh BD, Chen C. Phase II trial of hypofractionated IMRT with temozolomide for patients with newly diagnosed glioblastoma multiforme. Int $\mathrm{J}$ Radiat Oncol Biol Phys. 2012;84:655-60. doi: 10.1016/j. ijrobp.2012.01.035.

32. Rock K, McArdle O, Forde P, Dunne M, Fitzpatrick D, O`Neill B, Faul C. A clinical review of treatment outcomes in glioblastoma multiforme--the validation in a non-trial population of the results of a randomised Phase III clinical trial: has a more radical approach improved survival? Br J Radiol. 2012;85:e729-33. doi: 10.1259/bjr/83796755.

33. Kong DS, Lee JI, Kim JH, Kim ST, Kim WS, Suh YL, Dong SM, Nam DH. Phase II trial of low-dose continuous 
(metronomic) treatment of temozolomide for recurrent glioblastoma. Neuro Oncol. 2010;12:289-96.doi:10.1093/ neuonc/nop030.

34. Omuro A, Chan TA, Abrey LE, Khasraw M, Reiner AS, Kaley TJ, Deangelis LM, Lassman, AB, Nolan CP, Gavrilovic IT, Hormigo A, Salvant C, Heguy A, Kaufman A, Huse JT, Panageas KS, Hottinger AF, Mellinghoff I. Phase II trial of continuous low-dose temozolomide for patients with recurrent malignant glioma. Neuro Oncol. 2013;15:242-50. doi: 10.1093/neuonc/nos295.

35. Ruhlmann $\mathrm{CH}$, Herrstedt J. Safety evaluation of aprepitant for the prevention of chemotherapy-induced nausea and vomiting. Expert Opin Drug Saf. 2011;10:449-62. doi: 10.1517/14740338.2011.563235.

36. Chrisp P. Aprepitant: the evidence for its place in the prevention of chemotherapy-induced nausea and vomiting Core Evid. 2007; 2: 15-30.

37. Dando TM, Perry CM. Aprepitant: a review of its use in the prevention of chemotherapy-induced nausea and vomiting. Drugs. 2004;64:777-94.

38. Navari RM. Aprepitant: a neurokinin-1 receptor antagonist for the treatment of chemotherapy-induced nausea and vomiting. Expert Rev Anticancer Ther. 2004;4:715-24. PubMed PMID: 15485308 .

39. dos Santos LV, Souza FH, Brunetto AT, Sasse AD, da Silveira Nogueira Lima JP. Neurokinin-1 receptor antagonists for chemotherapy-induced nausea and vomiting: a systematic review. J Natl Cancer Inst. 2012;104:1280-92. doi: 10.1093/jnci/djs335.

40. Aapro MS, Schmoll HJ, Jahn F, Carides AD, Webb RT. Review of the efficacy of aprepitant for the prevention of chemotherapy-induced nausea and vomiting in a range of tumor types. Cancer Treat Rev. 2013;39:113-7. doi: 10.1016/j.ctrv.2012.09.002.

41. Muñoz M, González-Ortega A, Rosso M, Robles-Frias MJ, Carranza A, Salinas-Martín MV, Coveñas R. The substance P/neurokinin-1 receptor system in lung cancer: Focus on the antitumor action of neurokinin-1 receptor antagonists. Peptides. 2012;38:318-25. doi: 10.1016/j. peptides.2012.09.024.

42. Muñoz M and Rosso M. The NK-1 receptor antagonist aprepitant as a broad spectrum antitumor drug. Invest New Drugs 2010; 28:187-193.

43. Muñoz M, Rosso M, Coveñas R. The NK-1 Receptor: A New Target in Cancer Therapy. Curr Drug Target 2011;12: 909-921.

44. Muñoz M, Coveñas R. NK-1 receptor antagonists: a new generation of anticancer drugs. Mini Rev Med Chem 2012;12: 593-599.

45. Muñoz M, Rosso M, Perez A, Coveñas R, Rosso R, Zamarriego C, Piruat JI. The NK1 receptor is involved in the antitumoral action of L-733,060 and the mitogenic action of substance $\mathrm{P}$ on neuroblastoma and glioma cell lines. Neuropeptides 2005; 39:427-32.
46. Kast RE. Why cerebellar glioblastoma is rare and how that indicates adjunctive use of the FDA-approved anti-emetic aprepitant might retard cerebral glioblastoma growth: a new hypothesis to an old question. Clin Transl Oncol. 2009;11:408-10. PubMed PMID: 19574198.

47. Kast RE. Glioblastoma: synergy of growth promotion between CCL5 and NK-1R can be thwarted by blocking CCL5 with miraviroc, an FDA approved anti-HIV drug and blocking NK-1R with aprepitant, an FDA approved anti-nausea drug. J Clin Pharm Ther. 2010;35:657-63. doi: 10.1111/j.1365-2710.2009.01148.x.

48. Muñoz M, Martinez-Armesto J, Coveñas R. NK-1 receptor antagonists as antitumor drugs: a survey of the literature from 2000 to 2011. Expert Opin Ther Pat. 2012;22:735-46. doi: 10.1517/13543776.2012.697153.

49. Kramer MS, Cutler N, Feighner J. Distinct mechanism for antidepressant activity by blockade of central substance $\mathrm{P}$ receptors. Science, 1998;281:1640-5.

50. Hennig IM, Laissue JA, Horisberger U, Reubi JC. Substance-P receptors in human primary neoplasms: tumoral and vascular localization. Int J Cancer 1995;61: 786-92.

51. Castelli F, Tomasoni LR, Matteelli A. Advances in the treatment of malaria. Mediterr J Hematol Infect Dis. 2012;4:e2012064. doi: 10.4084/MJHID.2012.064.

52. Efferth T, Dunstan H, Sauerbrey A, Miyachi H, Chitambar CR. The antimalarial artesunate is also active against cancer. Int J Oncol 2001;18:767-73.

53. Efferth T, Rücker G, Falkenberg M, Manns D, Olbrich A, Fabry U, Osieka R. Detection of apoptosis in KG1a leukemic cells treated with investigational drugs. Arzneimittelforschung. 1996;46:196-200.

54. Efferth T. Molecular pharmacology and pharmacogenomics of artemisinin and its derivatives in cancer cells. Curr Drug Targets 2006;7:407-21.

55. Efferth T, Dunstan H, Sauerbrey A, Miyachi H, Chitambar CR. The anti-malarial artesunate is also active against cancer. Int J Oncol 2001;18:767-73.

56. Efferth T, Davey M, Olbrich A, Rücker G, Gebhart E, Davey R. Activity of drugs from traditional Chinese medicine toward sensitive and MDR1- or MRP1overexpressing multidrug-resistant human CCRF-CEM leukemia cells. Blood Cells Mol Dis 2002;28:160-8.

57. Davis TM, Binh TQ, Ilett KF, Batty KT, Phuöng HL, Chiswell GM, Phuong VD, Agus C. Penetration of dihydroartemisinin into cerebrospinal fluid after administration of intravenous artesunate in severe falciparum malaria. Antimicrob Agents Chemother. 2003;47:368-70. PubMed PMID: 12499215

58. Efferth T, Briehl MM, Tome ME. Role of antioxidant genes for the activity of artesunate against tumor cells. Int J Oncol 2003;23:1231-5.

59. Efferth T, Oesch F. Oxidative stress response of tumor cells: microarray-based comparison between artemisinins and 
anthracyclines. Biochem Pharmacol 2004;68:3-10.

60. Efferth T, Volm M. Glutathione-related enzymes contribute to resistance of tumor cells and low toxicity in normal organs to artesunate. In Vivo 2005;19: 225-32.

61. Aisen P. Transferrin receptor 1. Int J Biochem Cell Biol. 2004;36:2137-43. PubMed PMID: 15313461.

62. Calzolari A, Oliviero I, Deaglio S, Mariani G, Biffoni M, Sposi NM, Malavasi F, Peschle C, Testa U. Transferrin receptor 2 is frequently expressed in human cancer cell lines. Blood Cells Mol Dis. 2007;39:82-91. PubMed PMID: 17428703.

63. Kang MK, Kang SK. Tumorigenesis of chemotherapeutic drug-resistant cancer stem-like cells in brain glioma. Stem Cells Dev. 2007;16:837-47. PubMed PMID: 17999604.

64. Efferth T, Benakis A, Romero MR, Tomicic M, Rauh R, Steinbach D, Hafer R, Stamminger T, Oesch F, Kaina B, Marschall M. Enhancement of cytotoxicity of artemisinins toward cancer cells by ferrous iron. Free Radic Biol Med 2004;37: 998-1009.

65. Efferth T, Sauerbrey A, Olbrich A, Gebhart E, Rauch P, Weber HO, Hengstler JG, Halatsch ME, Volm M, Tew KD, Ross DD, Funk JO. Molecular modes of action of artesunate in tumor cell lines. Mol Pharmacol 2003;64:382-94.

66. Berdelle N, Nikolova T, Quiros S, Efferth T, Kaina B. Artesunate induces oxidative DNA damage, sustained DNA double-strand breaks, and the ATM/ATR damage response in cancer cells. Mol Cancer Ther. 2011;10:2224-33.

67. Karpel-Massler G, Westhoff MA, Kast RE, Wirtz CR, Halatsch ME. Erlotinib in glioblastoma: lost in translation? Anticancer Agents Med Chem. 2011;11:748-55. PubMed PMID: 21707495.

68. Karpel-Massler G, Wirtz CR, Halatsch ME. Drug combinations enhancing the antineoplastic effects of erlotinib in high-grade glioma. Recent Pat Anticancer Drug Discov. 2011;6:384-94. doi: 10.2174/157489211796957748.

69. Loew S, Schmidt U, Unterberg A, Halatsch ME. The epidermal growth factor receptor as a therapeutic target in glioblastoma multiforme and other malignant neoplasms. Anticancer Agents Med Chem. 2009;9:703-15. PubMed PMID: 19601750.

70. Efferth T, Ramirez T, Gebhart E, Halatsch ME. Combination treatment of glioblastoma multiforme cell lines with the anti-malarial artesunate and the epidermal growth factor receptor tyrosine kinase inhibitor OSI-774. Biochem Pharmacol 2004;67:1689-700.

71. Efferth T, Giaisi M, Merling A, Krammer PH, Li-Weber M. Artesunate induces ROS-mediated apoptosis in doxorubicin-resistant T leukemia cells. PLoS One 2007; 2: e693.

72. Reichert S, Reinboldt V, Hehlgans S, Efferth T, Rödel C, Rödel F. A radiosensitizing effect of artesunate in glioblastoma cells is associated with a diminished expression of the inhibitor of apoptosis protein survivin.
Radiother Oncol. 2012;103:394-401. doi: 10.1016/j. radonc.2012.03.018.

73. Zhao Y, Jiang W, Li B, Yao Q, Dong J, Cen Y, Pan X, Li J, Zheng J, Pang X, Zhou H. Artesunate enhances radiosensitivity of human non-small cell lung cancer A549 cells via increasing NO production to induce cell cycle arrest at G2/M phase. Int Immunopharmacol. 2011;11:203946. doi:10.1016/j.intimp.2011.08.017.

74. Glennås A, Kvien TK, Andrup O, Clarke-Jenssen O, Karstensen B, Brodin U. Auranofin is safe and superior to placebo in elderly-onset rheumatoid arthritis. $\mathrm{Br} \mathrm{J}$ Rheumatol. 1997;36:870-7. PubMed PMID: 9291856.

75. Kean WF, Hart L, Buchanan WW. Auranofin. Br J Rheumatol. 1997;36:560-72.

76. Choksi S, Lin Y, Pobezinskaya Y, Chen L, Park C, Morgan M, Li T, Jitkaew S, Cao X, Kim YS, Kim HS, Levitt P, Shih G, Birre M, Deng CX, Liu ZG. A HIF-1 target, ATIA, protects cells from apoptosis by modulating the mitochondrial thioredoxin, TRX2. Mol Cell. 2011;42:597609. doi: 10.1016/j.molcel.2011.03.030.

77. Becker K, Gromer S, Schirmer RH, Müller S. Thioredoxin reductase as a pathophysiological factor and drug target. Eur J Biochem. 2000;267:6118-25.

78. Kemerdere R, Kacira T, Hanimoglu H, Kucur M, Tanriverdi T, Canbaz B. Tissue and Plasma Thioredoxin Reductase Expressions in Patients with Glioblastoma Multiforme. J Neurol Surg A Cent Eur Neurosurg. 2013 Mar 19. [Epub ahead of print] PMID: 23512591

79. Powis G, Kirkpatrick DL. Thioredoxin signaling as a target for cancer therapy. Curr Opin Pharmacol. 2007;7:392-7.

80. Biaglow JE, Miller RA. The thioredoxin reductase/ thioredoxin system: novel redox targets for cancer therapy. Cancer Biol Ther. 2005;4:6-13.

81. Drechsel DA, Patel M. Respiration-dependent $\mathrm{H} 2 \mathrm{O} 2$ removal in brain mitochondria via the thioredoxin/ peroxiredoxin system. J Biol Chem. 2010;285:27850-8. doi:10.1074/jbc.M110.101196.

82. Lopert P, Day BJ, Patel M. Thioredoxin reductase deficiency potentiates oxidative stress, mitochondrial dysfunction and cell death in dopaminergic cells. PLoS One. 2012;7:e50683. doi: 10.1371/journal.pone.0050683.

83. Wang L, Fu JN, Wang JY, Jin CJ, Ren XY, Tan Q, Li J, Yin HW, Xiong K, Wang TY, Liu XM, Zeng HH. Seleniumcontaining thioredoxin reductase inhibitor ethaselen sensitizes non-small cell lung cancer to radiotherapy. Anticancer Drugs. 2011;22:732-40. doi: 10.1097/ CAD.0b013e32834618bc.

84. Lan L, Zhao F, Wang Y, Zeng H. The mechanism of apoptosis induced by a novel thioredoxin reductase inhibitor in A549 cells: possible involvement of nuclear factorkappaB-dependent pathway. Eur J Pharmacol. 2007;555:8392.

85. van Horssen R, Willemse $M$, Haeger A, Attanasio F, Güneri T, Schwab A, Stock CM, Buccione R, Fransen JA, 
Wieringa B. Intracellular NAD $(\mathrm{H})$ levels control motility and invasion of glioma cells. Cell Mol Life Sci. 2013 Jan 10. [Epub ahead of print] PMID:23307072

86. Madeira JM, Gibson DL, Kean WF, Klegeris A. The biological activity of auranofin: implications for novel treatment of diseases. Inflammopharmacology. 2012;20:297-306. doi: 10.1007/s10787-012-0149-1.

87. Guidi F, Landini I, Puglia M, Magherini F, Gabbiani C, Cinellu MA, Nobili S, Fiaschi T, Bini L, Mini E, Messori L, Modesti A. Proteomic analysis of ovarian cancer cell responses to cytotoxic gold compounds. Metallomics. 2012;4:307-14. doi: 10.1039/c2mt00083k.

88. Sobhakumari A, Love-Homan L, Fletcher EV, Martin SM, Parsons AD, Spitz DR, Knudson CM, Simons AL. Susceptibility of human head and neck cancer cells to combined inhibition of glutathione and thioredoxin metabolism. PLoS One. 2012;7:e48175. doi: 10.1371/ journal.pone.0048175.

89. Kenig S, Alonso MB, Mueller MM, Lah TT. Glioblastoma and endothelial cells cross-talk, mediated by SDF-1, enhances tumour invasion and endothelial proliferation by increasing expression of cathepsins $\mathrm{B}, \mathrm{S}$, and MMP-9. Cancer Lett. 2010;289:53-61. doi: 10.1016/j. canlet.2009.07.014.

90. Gole B, Durán Alonso MB, Dolenc V, Lah T. Posttranslational regulation of cathepsin $\mathrm{B}$, but not of other cysteine cathepsins, contributes to increased glioblastoma cell invasiveness in vitro. Pathol Oncol Res. 2009;15:71123.doi: 10.1007/s12253-009-9175-8.

91. Colin C, Voutsinos-Porche B, Nanni I, Fina F, Metellus P, Intagliata D, Baeza N, Bouvier C, Delfino C, Loundou A, Chinot O, Lah T, Kos J, Martin PM, Ouafik L, FigarellaBranger D. High expression of cathepsin B and plasminogen activator inhibitor type-1 are strong predictors of survival in glioblastomas. Acta Neuropathol. 2009;118:745-54. doi: 10.1007/s00401-009-0592-2.

92. Strojnik T, Kos J, Zidanik B, Golouh R, Lah T. Cathepsin $\mathrm{B}$ immunohistochemical staining in tumor and endothelial cells is a new prognostic factor for survival in patients with brain tumors. Clin Cancer Res. 1999;5:559-67. PubMed PMID: 10100707.

93. Lakka SS, Gondi CS, Yanamandra N, Olivero WC, Dinh DH, Gujrati M, Rao JS. Inhibition of cathepsin B and MMP-9 gene expression in glioblastoma cell line via RNA interference reduces tumor cell invasion, tumor growth and angiogenesis. Oncogene. 2004;23:4681-9.

94. Kast RE. Glioblastoma invasion, cathepsin B, and the potential for both to be inhibited by auranofin, an old anti-rheumatoid arthritis drug. Cent Eur Neurosurg. 2010;71:139-42. doi: 10.1055/s-0029-1242756.

95. Jørgensen CH, Pedersen B, Tønnesen H. The efficacy of disulfiram for the treatment of alcohol use disorder. Alcohol Clin Exp Res. 2011;35:1749-58. doi: 10.1111/j.15300277.2011.01523.x.
96. Johansson B. A review of the pharmacokinetics and pharmacodynamics of disulfiram and its metabolites. Acta Psychiatr Scand Suppl. 1992;369:15-26.

97. Liu P, Brown S, Goktug T, Channathodiyil P, Kannappan V, Hugnot JP, Guichet PO, Bian X, Armesilla AL, Darling JL, Wang W. Cytotoxic effect of disulfiram/copper on human glioblastoma cell lines and ALDH-positive cancerstem-like cells. Br J Cancer. 2012;107:1488-97. doi: 10.1038/bjc.2012.442.

98. Liu P, Brown S, Channathodiyil P, Kannappan V, Armesilla AL, Darling JL, Wang W. Reply: Cytotoxic effect of disulfiram/copper on human glioblastoma cell lines and ALDH-positive cancer-stem-like cells. Br J Cancer. 2013 Jan 22. doi:10.1038/bjc.2013.19. [Epub ahead of print] PubMed PMID: 23340450.

99. Xu B, Shi P, Fombon IS, Zhang Y, Huang F, Wang W, Zhou S. Disulfiram/copper complex activated JNK/c-jun pathway and sensitized cytotoxicity of doxorubicin in doxorubicin resistant leukemia HL60 cells. Blood Cells Mol Dis. 2011;47:264-9. doi: 10.1016/j.bcmd.2011.08.004.

100. Yip NC, Fombon IS, Liu P, Brown S, Kannappan V, Armesilla AL, Xu B, Cassidy J, Darling JL, Wang W. Disulfiram modulated ROS-MAPK and NFאB pathways and targeted breast cancer cells with cancer stem cell-like properties. Br J Cancer. 2011;104:1564-74. doi: 10.1038/ bjc.2011.126.

101. Guo X, Xu B, Pandey S, Goessl E, Brown J, Armesilla AL, Darling JL, Wang W. Disulfiram/copper complex inhibiting NFkappaB activity and potentiating cytotoxic effect of gemcitabine on colon and breast cancer cell lines. Cancer Lett. 2010;290:104-13. doi:10.1016/j.canlet.2009.09.002.

102. Wang W, McLeod HL, Cassidy J. Disulfiram-mediated inhibition of NF-kappaB activity enhances cytotoxicity of 5-fluorouracil in human colorectal cancer cell lines. Int $\mathbf{J}$ Cancer. 2003;104:504-11. PubMed PMID: 12584750.

103. Chen D, Dou QP. New uses for old copper-binding drugs: converting the pro-angiogenic copper to a specific cancer cell death inducer. Expert Opin Ther Targets. 2008;12:73948. doi: 10.1517/14728222.12.6.739 .

104. Ketola K, Kallioniemi O, Iljin K. Chemical biology drug sensitivity screen identifies sunitinib as synergistic agent with disulfiram in prostate cancer cells PLoS One. 2012; 7: e51470. doi: 10.1371/journal.pone.

105. Morrison BW, Doudican NA, Patel KR, Orlow SJ. Disulfiram induces copper-dependent stimulation of reactive oxygen species and activation of the extrinsic apoptotic pathway in melanoma. Melanoma Res. 2010;20:11-20. doi:10.1097/CMR.0b013e328334131d.

106. Wickström M, Danielsson K, Rickardson L, Gullbo $\mathrm{J}$, Nygren $\mathrm{P}$, Isaksson A, Larsson $\mathrm{R}$, Lövborg $\mathrm{H}$. Pharmacological profiling of disulfiram using human tumor cell lines and human tumor cells from patients. Biochem Pharmacol. 2007;73:25-33. PubMed PMID: 17026967.

107. Yakisich JS, Sidén A, Eneroth P, Cruz M. Disulfiram is a 
potent in vitro inhibitor of DNA topoisomerases. Biochem Biophys Res Commun. 2001;289:586-90. PubMed PMID: 11716515.

108. Sauna ZE, Peng XH, Nandigama K, Tekle S, Ambudkar $\mathrm{SV}$. The molecular basis of the action of disulfiram as a modulator of the multidrug resistance-linked ATP binding cassette transporters MDR1 (ABCB1) and MRP1 (ABCC1). Mol Pharmacol. 2004;65:675-84. PubMed PMID: 14978246.

109. Sauna ZE, Shukla S, Ambudkar SV. Disulfiram, an old drug with new potential therapeutic uses for human cancers and fungal infections. Mol Biosyst. 2005;1:127-34. PubMed PMID: 16880974.

110. Brar SS, Grigg C, Wilson KS, Holder WD Jr, Dreau D, Austin C, Foster M, Ghio AJ, Whorton AR, Stowell GW, Whittall LB, Whittle RR, White DP, Kennedy TP. Disulfiram inhibits activating transcription factor/cyclic AMP-responsive element binding protein and human melanoma growth in a metal-dependent manner in vitro, in mice and in a patient with metastatic disease. Mol Cancer Ther. 2004;3:1049-60. PubMed PMID: 15367699.

111. Lövborg H, Oberg F, Rickardson L, Gullbo J, Nygren P, Larsson R. Inhibition of proteasome activity, nuclear factor-KappaB translocation and cell survival by the antialcoholism drug disulfiram. Int $\mathrm{J}$ Cancer. 2006;118:1577-80. PubMed PMID: 16206267.

112. Lin J, Haffner MC, Zhang Y, Lee BH, Brennen WN, Britton J, Kachhap SK, Shim JS, Liu JO, Nelson WG, Yegnasubramanian S, Carducci MA. Disulfiram is a DNA demethylating agent and inhibits prostate cancer cell growth. Prostate. 2011;71:333-43. doi: 10.1002/pros.21247.

113. Cvek B. Targeting malignancies with disulfiram (Antabuse): multidrug resistance, angiogenesis, and proteasome. Curr Cancer Drug Targets. 2011;11:332-7. PubMed PMID: 21247389.

114. Cvek B. Antabuse (disulfiram) as a pilot case of nonprofit drug. Int J Cancer. 2010;127:2486. doi: 10.1002/ijc.25237. PubMed PMID: 20143396.

115. Cvek B, Dvorak Z. The value of proteasome inhibition in cancer. Can the old drug, disulfiram, have a bright new future as a novel proteasome inhibitor? Drug Discov Today. 2008;13:716-22. doi: 10.1016/j.drudis.2008.05.003.

116. Cvek B, Dvorak Z. Targeting of nuclear factor-kappaB and proteasome by dithiocarbamate complexes with metals. Curr Pharm Des. 2007;13:3155-67.

117. Conticello C, Martinetti D, Adamo L, Buccheri S, Giuffrida R, Parrinello N, Lombardo L, Anastasi G, Amato G, Cavalli M, Chiarenza A, De Maria R, Giustolisi R, Gulisano M, Di Raimondo F. Disulfiram, an old drug with new potential therapeutic uses for human hematological malignancies. Int J Cancer. 2012;131:2197-203. doi: 10.1002/ijc.27482.

118. Iljin K, Ketola K, Vainio P, Halonen P, Kohonen P, Fey V, Grafström RC, Perälä M, Kallioniemi O. Highthroughput cell-based screening of 4910 known drugs and drug-like small molecules identifies disulfiram as an inhibitor of prostate cancer cell growth. Clin Cancer Res. 2009;15:6070-8. doi:10.1158/1078-0432.CCR-09-1035.

119. Cvek B, Milacic V, Taraba J, Dou QP. Ni(II), Cu(II), and $\mathrm{Zn}$ (II) diethyldithiocarbamate complexes show various activities against the proteasome in breast cancer cells. J Med Chem. 2008;51:6256-8. doi: 10.1021/jm8007807.

120. Cvek B. Nonprofit drugs as the salvation of the world's healthcare systems: the case of Antabuse (disulfiram). Drug Discov Today. 2012;17:409-12. doi: 10.1016/j. drudis.2011.12.010. PubMed PMID: 22192884.

121. Rasper M, Schäfer A, Piontek G, Teufel J, Brockhoff G, Ringel F, Heindl S, Zimmer C, Schlegel J. Aldehyde dehydrogenase 1 positive glioblastoma cells show brain tumor stem cell capacity. Neuro Oncol. 2010; 12(10): 1024-1033. doi: 10.1093/neuonc/noq070.

122. Rappa F, Cappello F, Halatsch ME, Scheuerle A, Kast RE. Aldehyde dehydrogenase and HSP90 co-localize in human glioblastoma biopsy cells. Biochimie 2013;95(4):782-6. doi: 10.1016/j.biochi.2012.11.007.

123. Schäfer A, Teufel J, Ringel F, Bettstetter M, Hoepner I, Rasper M, Gempt J, Koeritzer J, Schmidt-Graf F, Meyer B, Beier CP, Schlegel J. Aldehyde dehydrogenase 1A1--a new mediator of resistance to temozolomide in glioblastoma. Neuro Oncol. 2012;14:1452-64. doi: 10.1093/neuonc/ $\operatorname{nos} 270$.

124. Quemener V, Moulinoux JP, Martin C, Darcel F, Guegan Y, Faivre J, Quash GA. Aldehyde dehydrogenase activity in xenografted human brain tumor in nude mice. Preliminary results in human glioma biopsies. J Neurooncol. 1990;9:115-23.PubMed PMID: 2262798.

125. Benayoun L, Shaked Y. In vitro enrichment of tumorinitiating cells from human established cell lines. Curr Protoc Stem Cell Biol. 2013 Feb;Chapter 3:Unit3.7.doi: 10.1002/9780470151808.sc0307s24.

126. Hothi P, Martins TJ, Chen L, Deleyrolle L, Yoon JG, Reynolds B, Foltz G. High-throughput chemical screens identify disulfiram as an inhibitor of human glioblastoma stem cells. Oncotarget. 2012;3(10):1124-36.

127. Kast RE, Belda-Iniesta C. Suppressing glioblastoma stem cell function by aldehyde dehydrogenase inhibition with chloramphenicol or disulfiram as a new treatment adjunct: an hypothesis. Curr Stem Cell Res Ther. 2009;4(4):314-7. PubMed PMID: 19500061.

128. O'Brien A, Barber JE, Reid S, Niknejad N, Dimitroulakos J. Enhancement of cisplatin cytotoxicity by disulfiram involves activating transcription factor 3 . Anticancer Res. 2012;32:2679-88. PubMed PMID: 22753726.

129. Dalla Pozza E, Donadelli M, Costanzo C, Zaniboni T, Dando I, Franchini M, Arpicco S, Scarpa A, Palmieri M. Gemcitabine response in pancreatic adenocarcinoma cells is synergistically enhanced by dithiocarbamate derivatives. Free Radic Biol Med. 201;50:926-33. doi:10.1016/j. freeradbiomed.2011.01.001. 
130. Triscott J, Lee C, Hu K, Fotovati A, Berns R, Pambid M, Luk M, Kast RE, Kong E, Toyota E, Yip S, Toyota B, Dunn SE. Disulfiram, a drug widely used to control alcoholism, suppresses the self-renewal of glioblastoma and over-rides resistance to temozolomide. Oncotarget. 2012;3:1112-23. PubMed PMID: 23047041.

131. Budman DR, Calabro A. In vitro search for synergy and antagonism: evaluation of docetaxel combinations in breast cancer cell lines. Breast Cancer Res Treat. 2002;74:41-6. PubMed PMID: 12150451.

132. Moreb JS, Ucar D, Han S, Amory JK, Goldstein AS, Ostmark B, Chang LJ. The enzymatic activity of human aldehyde dehydrogenases $1 \mathrm{~A} 2$ and 2 (ALDH1A2 and ALDH2) is detected by Aldefluor, inhibited by diethylaminobenzaldehyde and has significant effects on cell proliferation and drug resistance. Chem Biol Interact. 2012;195:52-60. doi: 10.1016/j.cbi.2011.10.007.

133. Paranjpe A, Srivenugopal KS. Degradation of NF- $\kappa B$, p53 and other regulatory redox-sensitive proteins by thiolconjugating and -nitrosylating drugs in human tumor cells. Carcinogenesis. 2013 Feb 15. [Epub ahead of print] PubMed PMID: 23354308.

134. Dufour P, Lang JM, Giron C, Duclos B, Haehnel P, Jaeck D, Jung JM, Oberling F. Sodium dithiocarb as adjuvant immunotherapy for high risk breast cancer: a randomized study. Biotherapy. 1993;6:9-12.

135. Suh JJ, Pettinati HM, Kampman KM, O’Brien CP. The status of disulfiram: a half of a century later. J Clin Psychopharmacol. 2006;26:290-302.

136. Lewison EF. Spontaneous regression of breast cancer. Prog Clin Biol Res. 1977;12:47-53. PMID: 918117

137. Chen D, Cui QC, Yang H, Dou QP. Disulfiram, a clinically used anti-alcoholism drug and copper-binding agent, induces apoptotic cell death in breast cancer cultures and xenografts via inhibition of the proteasome activity. Cancer Res. 2006;66:10425-33.

138. Yu Z, Wang F, Milacic V, Li X, Cui QC, Zhang B, Yan B, Dou QP. Evaluation of copper-dependent proteasomeinhibitory and apoptosis-inducing activities of novel pyrrolidine dithiocarbamate analogues. Int J Mol Med. 2007;20:919-25. PubMed PMID: 17982703.

139. Loo TW, Bartlett MC, Clarke DM. Disulfiram metabolites permanently inactivates human multidrug resistance P-glycoprotein. Mol Pharm. 2004;1:426-33. PubMed PMID: 16028354.

140. Kaina B, Margison GP, Christmann M. Targeting O6methylguanine-DNA methyltransferase with specific inhibitors as a strategy in cancer therapy. Cell Mol Life Sci. 2010;67:3663-3681.

141. Jiang G, Li LT, Xin Y, Zhang L, Liu YQ, Zheng JN. Strategies to improve the killing of tumors using temozolomide: targeting the DNA repair protein MGMT. Curr Med Chem. 2012;19:3886-92. PubMed PMID: 22788764 .
142. Fukushima T, Takeshima H, Kataoka H. Anti-glioma therapy with temozolomide and status of the DNA-repair gene MGMT. Anticancer Res. 2009;29:4845-54. PubMed PMID: 20032445.

143. Srivenugopal KS, Paranjpe A. Potent redox-based inhibition of human MGMT for improving the efficacy of anticancer alkylating agents. Proc Amer Ass Cancer Res. 52, p.1321, 2011.

144. Niture SK, Velu CS, Bailey N, Srivenugopal KS. Human MGMT is a prime target for inactivation by oxidative stress, mediated by glutathionylation and oxidation of the active site cysteine145. Proc Amer Assoc Cancer Res. 2004;45:355, 2004.

145. Cohen KJ, Pollack IF, Zhou T, Buxton A, Holmes EJ, Burger PC, Brat DJ, Rosenblum MK, Hamilton RL, Lavey RS, Heideman RL. Temozolomide in the treatment of highgrade gliomas in children: a report from the Children's Oncology Group. Neuro Oncol. 2011;13(3):317-23. doi: 10.1093/neuonc/noq191.

146. Watanabe R, Nakasu Y, Tashiro H, Mitsuya K, Ito I, Nakasu $\mathrm{S}$, Nakajima T. O6-methylguanine DNA methyltransferase expression in tumor cells predicts outcome of radiotherapy plus concomitant and adjuvant temozolomide therapy in patients with primary glioblastoma. Brain Tumor Pathol. 2011;28:127-135.

147. Quinn JA, Jiang SX, Reardon DA, Desjardins A, Vredenburgh JJ, Rich JN, Gururangan S, Friedman AH, Bigner DD, Sampson JH, McLendon RE, Herndon JE 2nd, Walker A, Friedman HS. Phase II trial of temozolomide plus o6-benzylguanine in adults with recurrent, temozolomideresistant malignant glioma. J Clin Oncol. 2009;27:1262-7. doi: 10.1200/JCO.2008.18.8417.

148. Guengerich, Fang Q, Liu L, Hachey DL, Pegg AE. O6alkylguanine-DNA alkyltransferase: low $\mathrm{pKa}$ and high reactivity of cysteine 145. Biochemistry. 2003;42:1096570. PubMed PMID: 12974631.

149. Niture SK, Velu CS, Smith QR, Bhat GJ, Srivenugopal KS. Increased expression of the MGMT repair protein mediated by cysteine prodrugs and chemopreventive natural products in human lymphocytes and tumor cell lines. Carcinogenesis 2006;28:378-389.

150. Matsuno T, Kariya R, Yano S, Morino-Koga S, Taura M, Suico MA, Shimauchi Y, Matsuyama S, Okamoto Y, Shuto T, Kai H, Okada S. Diethyldithiocarbamate induces apoptosis in HHV-8-infected primary effusion lymphoma cells via inhibition of the NF-KB pathway. Int J Oncol. 2012;40:1071-8. doi: 10.3892/ijo.2011.1313.

151. Skrott Z, Cvek B. Diethyldithiocarbamate complex with copper: the mechanism of action in cancer cells. Mini Rev Med Chem. 2012;12:1184-92. PubMed PMID: 22931589.

152. Lehmann K, Rickenbacher A, Jang JH, Oberkofler CE, Vonlanthen R, von Boehmer L, Humar B, Graf R, Gertsch P, Clavien PA. New insight into hyperthermic intraperitoneal chemotherapy: induction of oxidative stress dramatically enhanced tumor killing in in vitro and 
in vivo models. Ann Surg. 2012;256:730-7. doi: 10.1097/ SLA.0b013e3182737517.

153. Kast RE. Ritonavir and disulfiram may be synergistic in lowering active interleukin-18 levels in acute pancreatitis, and thereby hasten recovery. JOP. 2008;9(3):350-3. PubMed PMID: 18469453.

154. Foley K, Kast RE, Altschuler EL. Ritonavir and disulfiram have potential to inhibit caspase-1 mediated inflammation and reduce neurological sequelae after minor blast exposure. Med Hypotheses. 2009;72:150-2. doi: 10.1016/j. mehy.2008.08.024.

155. Nishikawa S, Konno M, Hamabe A, Hasegawa S, Kano Y, Ohta K, Fukusumi T, Sakai D, Kudo T, Haraguchi N, Satoh T, Takiguchi S, Mori M, Doki Y, Ishii H. Aldehyde dehydrogenase high gastric cancer stem cells are resistant to chemotherapy. Int J Oncol. 2013 Feb 22. doi: 10.3892/ ijo.2013.1837.

156. FDA.gov. accessed 3 Feb 2013. http://www. fda.gov/Food/FoodIngredientsPackaging/

GenerallyRecognizedasSafeGRAS/

GRASSubstancesSCOGSDatabase/ucm261260.htm

157. Olmo M, Podzamczer D. A review of nelfinavir for the treatment of HIV infection. Expert Opin Drug Metab Toxicol. 2006;2:285-300. PubMed PMID: 16866614.

158. Chiosis G, Dickey CA, Johnson JL. A global view of Hsp90 functions. Nat Struct Mol Biol. 2013;20:1-4. doi: 10.1038/ nsmb.2481.

159. Kast RE, Halatsch ME. Matrix metalloproteinase-2 and -9 in glioblastoma: a trio of old drugs-captopril, disulfiram and nelfinavir-are inhibitors with potential as adjunctive treatments in glioblastoma. Arch Med Res. 2012;43:243-7. doi: 10.1016/j.arcmed.2012.04.005.

160. Khaliq Y, Gallicano K, Venance S, Kravcik S, Cameron DW. Effect of ketoconazole on ritonavir and saquinavir concentrations in plasma and cerebrospinal fluid from patients infected with human immunodeficiency virus. Clin Pharmacol Ther. 2000;68:637-46.

161. Shim JS, Rao R, Beebe K, Neckers L, Han I, Nahta R, Liu JO. Selective inhibition of HER2-positive breast cancer cells by the HIV protease inhibitor nelfinavir. J Natl Cancer Inst. 2012;104:1576-90. doi: 10.1093/jnci/djs396.

162. Brüning A, Gingelmaier A, Friese K, Mylonas I. New prospects for nelfinavir in non-HIV-related diseases. Curr Mol Pharmacol. 2010;3:91-7. PubMed PMID: 20359290.

163. Brüning A, Burger P, Vogel M, Rahmeh M, Gingelmaiers A, Friese K, Lenhard M, Burges A. Nelfinavir induces the unfolded protein response in ovarian cancer cells, resulting in ER vacuolization, cell cycle retardation and apoptosis. Cancer Biol Ther. 2009;8:226-32.

164. Brüning A, Rahmeh M, Gingelmaier A, Friese K. The mitochondria-independent cytotoxic effect of nelfinavir on leukemia cells can be enhanced by sorafenib-mediated mcl-1 downregulation and mitochondrial membrane destabilization Mol Cancer. 2010; 9:19. doi: 10.1186/1476-
4598-9-19

165. Chow WA, Jiang C, Guan M. Anti-HIV drugs for cancer therapeutics: back to the future? Lancet Oncol. 2009;10:6171. doi: 10.1016/S1470-2045(08)70334-6.

166. Brüning A, Friese K, Burges, Ioannis Mylonas I. Tamoxifen enhances the cytotoxic effects of nelfinavir in breast cancer cells. Breast Cancer Res. 2010;12: R45. doi: 10.1186/bcr2602.

167. Brüning A. Analysis of nelfinavir-induced endoplasmic reticulum stress. Methods Enzymol. 2011;491:127-42. doi: 10.1016/B978-0-12-385928-0.00008-0.

168. Pyrko P, Kardosh A, Wang W, Xiong W, Schönthal $\mathrm{AH}$, Chen TC. HIV-1 protease inhibitors nelfinavir and atazanavir induce malignant glioma death by triggering endoplasmic reticulum stress. Cancer Res. 2007;67:109208.

169. Gills JJ, Lopiccolo J, Dennis PA. Nelfinavir, a new anticancer drug with pleiotropic effects and many paths to autophagy. Autophagy. 2008;4:107-9. PubMed PMID: 18000394.

170. Gills JJ, Lopiccolo J, Tsurutani J, Shoemaker RH, Best CJ, Abu-Asab MS, Borojerdi J, Warfel NA, Gardner ER, Danish M, Hollander MC, Kawabata S, Tsokos M, Figg WD, Steeg PS, Dennis PA. Nelfinavir, A lead HIV protease inhibitor, is a broad-spectrum, anticancer agent that induces endoplasmic reticulum stress, autophagy, and apoptosis in vitro and in vivo. Clin Cancer Res. 2007;13:5183-94. PubMed PMID: 17785575.

171. Bono C, Karlin L, Harel S, Mouly E, Labaume S, Galicier L, Apcher S, Sauvageon H,Fermand JP, Bories JC, Arnulf B. The human immunodeficiency virus-1 protease inhibitor nelfinavir impairs proteasome activity and inhibits the proliferation of multiple myeloma cells invitro and in vivo. Haematologica. 2012;97:1101-9. doi: 10.3324/ haematol.2011.049981.

172. Cruickshanks N, Shervington L, Patel R, Munje C, Thakkar D, Shervington A. Can hsp90alpha-targeted siRNA combined with TMZ be a future therapy for glioma? Cancer Invest. 2010;28:608-14. doi: 10.3109/07357901003630967.

173. Lu X, Xiao L, Wang L, Ruden DM. Hsp90 inhibitors and drug resistance in cancer: the potential benefits of combination therapies of Hsp90 inhibitors and other anticancer drugs. Biochem Pharmacol. 2012;83(8):995-1004. doi: 10.1016/j.bcp.2011.11.011.

174. Ohba S, Hirose Y, Yoshida K, Yazaki T, Kawase T. Inhibition of $90-\mathrm{kD}$ heat shock protein potentiates the cytotoxicity of chemotherapeutic agents in human glioma cells. J Neurosurg. 2010;112(1):33-42. doi: 10.3171/2009.3.JNS081146.

175. Zhu H, Woolfenden S, Bronson RT, Jaffer ZM, Barluenga S, Winssinger N, Rubenstein AE, Chen R, Charest A. The novel Hsp90 inhibitor NXD30001 induces tumor regression in a genetically engineered mouse model of glioblastoma multiforme. Mol Cancer Ther. 2010;9:2618- 
26. doi:10.1158/1535-7163.MCT-10-0248

176. Siegelin MD, Habel A, Gaiser T. 17-AAG sensitized malignant glioma cells to death-receptor mediated apoptosis. Neurobiol Dis. 2009;33:243-9. doi:10.1016/j. nbd.2008.10.005

177. Premkumar DR, Arnold B, Jane EP, Pollack IF. Synergistic interaction between 17-AAG and phosphatidylinositol 3 -kinase inhibition in human malignant glioma cells. Mol Carcinog. 2006;45:47-59.

178. Dungey FA, Caldecott KW, Chalmers AJ. Enhanced radiosensitization of human glioma cells by combining inhibition of poly(ADP-ribose) polymerase witinhibition of heat shock protein 90. Mol Cancer Ther. 2009;8:2243-54. doi:10.1158/1535-7163.MCT-09-0201.

179. Gaspar N, Sharp SY, Eccles SA, Gowan S, Popov S, Jones C, Pearson A, Vassal G, Workman P. Mechanistic evaluation of the novel HSP90 inhibitor NVP-AUY922 in adult and pediatric glioblastoma. Mol Cancer Ther. 2010;9:1219-33. doi:10.1158/1535-7163.MCT-09-0683.

180. Sauvageot CM, Weatherbee JL, Kesari S, Winters SE, Barnes J, Dellagatta J, Ramakrishna NR, Stiles CD, Kung AL, Kieran MW, Wen PY. Efficacy of the HSP90 inhibitor 17-AAG in human glioma cell lines and tumorigenic glioma stem cells. Neuro Oncol. 2009;11:109-21. doi: 10.1215/15228517-2008-060

181. Tian X, Ye J, Alonso-Basanta M, Hahn SM, Koumenis C, Dorsey JF. Modulation of CCAAT/enhancer binding protein homologous protein (CHOP)-dependent DR5 expression by nelfinavir sensitizes glioblastoma multiforme cells to tumor necrosis factor-related apoptosis-inducing ligand (TRAIL). J Biol Chem. 2011;286(33):29408-16. doi:10.1074/jbc.M110.197665.

182. Nakada M, Okada Y, Yamashita J. The role of matrix metalloproteinases in glioma invasion. Front Biosci. 2003;8:e261-9.

183. Chintala SK, Tonn JC, Rao JS. Matrix metalloproteinases and their biological function in human gliomas. Int J Dev Neurosci. 1999;17:495-502.

184. Kim MS, Kwak HJ, Lee JW, Kim HJ, Park MJ, Park JB, Choi KH, Yoo H, Shin SH, Shin WS, Song ES, Lee SH. 17-Allylamino-17-demethoxygeldanamycin down-regulates hyaluronic acid-induced glioma invasion by blocking matrix metalloproteinase-9 secretion. Mol Cancer Res. 2008;6:1657-65. doi:10.1158/1541-7786.MCR-08-0034.

185. Kumar S, Bryant CS, Chamala S, Qazi A, Seward S, Pal J, Steffes CP, Weaver DW, Morris R, Malone JM, Shammas MA, Prasad M, Batchu RB. Ritonavir blocks AKT signaling, activates apoptosis and inhibits migration and invasion in ovarian cancer cells. Mol Cancer. 2009;8:26. doi: 10.1186/1476-4598-8-26.

186. Gary-Bobo G, Houssaini A, Amsellem V, Rideau D, Pacaud P, Perrin A, Brégeon J, Marcos E, DuboisRandé JL, Sitbon O, Savale L, Adnot S. Effects of HIV protease inhibitors on progression of monocrotaline- and hypoxia-induced pulmonary hypertension in rats. Circulation. 2010;122:1937-47. doi:10.1161/ CIRCULATIONAHA.110.973750.

187. Gupta AK, Cerniglia GJ, Mick R, McKenna WG, Muschel RJ. HIV protease inhibitors block Akt signaling and radiosensitize tumor cells both in vitro and in vivo. Cancer Res. 2005;65:8256-65. PubMed PMID: 16166302.

188. Gupta AK, Li B, Cerniglia GJ, Ahmed MS, Hahn SM, Maity A. The HIV protease inhibitor nelfinavir downregulates Akt phosphorylation by inhibiting proteasomal activity and inducing the unfolded protein response. Neoplasia. 2007;9:271-8

189. Srirangam A, Mitra R, Wang M, Gorski JC, Badve S, Baldridge L, Hamilton J, Kishimoto H, Hawes J, Li L, Orschell CM, Srour EF, Blum JS, Donner D, Sledge GW, Nakshatri H, Potter DA. Effects of HIV protease inhibitor ritonavir on Akt-regulated cell proliferation in breast cancer. Clin Cancer Res. 2006;12:1883-96.

190. Xie L, Evangelidis T, Xie L, Bourne PE. Drug discovery using chemical systems biology: weak inhibition of multiple kinases may contribute to the anti-cancer effect of nelfinavir. PLoS Comput Biol. 2011;7:e1002037. doi: 10.1371/journal.pcbi.1002037.

191. Jiang Z, Pore N, Cerniglia GJ, Mick R, Georgescu MM, Bernhard EJ, Hahn SM, Gupta AK, Maity A. Phosphatase and tensin homologue deficiency in glioblastoma confers resistance to radiation and temozolomide that is reversed by the protease inhibitor nelfinavir. Cancer Res. 2007;67:446773.

192. Koul D. PTEN signaling pathways in glioblastoma. Cancer Biol Ther. 2008;7:1321-5.

193. McDowell KA, Riggins GJ, Gallia GL. Targeting the AKT pathway in glioblastoma. Curr Pharm Des. 2011;17:241120.

194. Pore N, Gupta AK, Cerniglia GJ, Jiang Z, Bernhard EJ, Evans SM, Koch CJ, Hahn SM, Maity A. Nelfinavir downregulates hypoxia-inducible factor 1alpha and VEGF expression and increases tumor oxygenation: implications for radiotherapy. Cancer Res. 2006;66:9252-9.

195. Pore N, Gupta AK, Cerniglia GJ, Maity A. HIV protease inhibitors decrease VEGF/HIF-1alpha expression and angiogenesis in glioblastoma cells. Neoplasia. 2006;8:88995.

196. Haupt A, Joberty G, Bantscheff M, Fröhlich H, Stehr H, Schweiger MR, Fischer A, Kerick M, Boerno ST, Dahl A, Lappe M, Lehrach H, Gonzalez C, Drewes G, Lange BM. Hsp90 inhibition differentially destabilises MAP kinase and TGF-beta signalling components in cancer cells revealed by kinase-targeted chemoproteomics. BMC Cancer. 2012;12:38. doi: 10.1186/1471-2407-12-38.

197. Noh H, Kim HJ, Yu MR, Kim WY, Kim J, Ryu JH, Kwon SH, Jeon JS, Han DC, Ziyadeh F. Heat shock protein 90 inhibitor attenuates renal fibrosis through degradation of transforming growth factor- $\beta$ type II receptor. Lab Invest. 
2012;92:1583-96. doi: 10.1038/labinvest.2012.127.

198. Shi L, Zhang Z, Fang S, Xu J, Liu J, Shen J, Fang F, Luo L, Yin Z. Heat shock protein 90 (Hsp90) regulates the stability of transforming growth factor beta-activated kinase 1 (TAK1) in interleukin-1beta-induced cell signaling. Mol Immunol. 2009;46:541-50. doi: 10.1016/j. molimm.2008.07.019.

199. Zhang K, Lu Y, Yang P, Li C, Sun H, Tao D, Liu Y, Zhang $\mathrm{S}$, Ma Y. HILI inhibits TGF- $\beta$ signaling by interacting with Hsp90 and promoting T $\beta$ R degradation. PLoS One. 2012;7(7):e41973. doi: 10.1371/journal.pone.0041973.

200. Rengan R, Mick R, Pryma D, Rosen MA, Lin LL, Maity AM, Evans TL, Stevenson JP, Langer CJ, Kucharczuk J, Friedberg J, Prendergast S, Sharkoski T, Hahn SM. A phase I trial of the HIV protease inhibitor nelfinavir with concurrent chemoradiotherapy for unresectable stage IIIA/ IIIB non-small cell lung cancer: a report of toxicities and clinical response. J Thorac Oncol. 2012;7:709-15. doi: 10.1097/JTO.0b013e3182435aa6.

201. Walmsley S, Bernstein B, King M, Arribas J, Beall G, Ruane P, Johnson M, Johnson D, Lalonde R, Japour A, Brun S, Sun E; M98-863 Study Team. Lopinavir-ritonavir versus nelfinavir for the initial treatment of HIV infection. N Engl J Med. 2002;346:2039-46.

202. Barillari G, Iovane A, Bacigalupo I, Palladino C, Bellino S, Leone P, Monini P, Ensoli B. Ritonavir or saquinavir impairs the invasion of cervical intraepithelial neoplasia cells via a reduction of MMP expression and activity. AIDS. 2012;26:909-19.

203. McRae AL, Brady KT. Review of sertraline and its clinical applications in psychiatric disorders. Expert Opin Pharmacother. 2001;2:883-92.

204. Sheehan DV, Kamijima K. An evidence-based review of the clinical use of sertraline in mood and anxiety disorders. Int Clin Psychopharmacol. 2009;24:43-60

205. Raysi Dehcordi S, De Paulis D, Marzi S, Ricci A, Cimini A, Cifone MG, Galzio RJ. Survival prognostic factors in patients with glioblastoma: our experience. J Neurosurg Sci. 2012;56:239-45. PubMed PMID: 22854592.

206. Fox SW, Lyon D, Farace E. Symptom clusters in patients with high-grade glioma. J Nurs Scholarsh. 2007;39:61-7.

207. Rooney AG, McNamara S, Mackinnon M, Fraser M, Rampling R, Carson A, Grant R. Screening for major depressive disorder in adults with glioma using the PHQ-9: a comparison of patient versus proxy reports. J Neurooncol. 2013 Feb 24. [Epub ahead of print] PubMed PMID: 23436131 .

208. Walker AJ, Grainge M, Bates TE, Card TR. Survival of glioma and colorectal cancer patients using tricyclic antidepressants post-diagnosis. Cancer Causes Control. 2012;23:1959-64. doi: 10.1007/s10552-012-0073-0.

209. Caudill JS, Brown PD, Cerhan JH, Rummans TA. Selective serotonin reuptake inhibitors, glioblastoma multiforme, and impact on toxicities and overall survival: the mayo clinic experience. Am J Clin Oncol. 2011;34:385-7. doi: 10.1097/ COC.0b013e3181e8461a.

210. Tzadok S, Beery E, Israeli M, Uziel O, Lahav M, Fenig E, Gil-Ad I, Weizman A, Nordenberg J. In vitro novel combinations of psychotropics and anti-cancer modalities in U87 human glioblastoma cells. Int J Oncol. 2010;37:104351.

211. Reddy KK, Lefkove B, Chen LB, Govindarajan B, Carracedo A, Velasco G, Carrillo CO, Bhandarkar SS, Owens MJ, Mechta-Grigoriou F, Arbiser JL. The antidepressant sertraline downregulates Akt and has activity against melanoma cells. Pigment Cell Melanoma Res. 2008;21:451-6. doi: 10.1111/j.1755-148X.2008.00481.x.

212. Arroll B, Doughty R, Andersen V. Investigation and management of congestive heart failure. BMJ. 2010;341:c3657. doi: 10.1136/bmj.c3657.

213. Brogden RN, Todd PA, Sorkin EM. Captopril. An update of its pharmacodynamic and pharmacokinetic properties, and therapeutic use in hypertension and congestive heart failure. Drugs. 1988;36:540-600.

214. Carpentier AF, Ferrari D, Bailon O, Ursu R, Banissi C, Dubessy AL, Belin C, Levy C. Steroid-sparing effects of angiotensin-II inhibitors in glioblastoma patients. Eur J Neurol. 2012;19:1337-42. doi:10.1111/j.14681331.2012.03766.x.

215. Kenna HA, Poon AW, de los Angeles CP, Koran LM. Psychiatric complications of treatment with corticosteroids: review with case report. Psychiatry Clin Neurosci. 2011;65:549-60. doi: 10.1111/j.1440-1819.2011.02260.x.

216. Dubovsky AN, Arvikar S, Stern TA, Axelrod L. The neuropsychiatric complications of glucocorticoid use: steroid psychosis revisited. Psychosomatics. 2012;53:10315. doi: 10.1016/j.psym.2011.12.007.

217. Roth P, Wick W, Weller M. Steroids in neurooncology: actions, indications, side-effects. Curr Opin Neurol. 2010;23:597-602. doi:10.1097/WCO.0b013e32833e5a5d.

218. Gustafson MP, Lin Y, New KC, Bulur PA, O`Neill BP, Gastineau DA, Dietz AB. Systemic immune suppression in glioblastoma: the interplay between CD14+HLA-DRlo/ neg monocytes, tumor factors, and dexamethasone. Neuro Oncol. 2010;12:631-44. doi: 10.1093/neuonc/noq001. Epub 2010 Feb 23.

219. Plosker GL, McTavish D. Captopril. A review of its pharmacology and therapeutic efficacy after myocardial infarction and in ischaemic heart disease. Drugs Aging. 1995;7:226-53.

220. Kleber FX, Reindl I, Wenzel M, Rodewyk P, Beil S, Kosloswki B, Doering W, Sabin GV, Hinzmann S, Winter UJ, et al. Experiences with ACE inhibitors early after acute myocardial infarction. Rationale and design of the German Multicenter Study on the Effects of Captopril on Cardiopulmonary Exercise parameters post myocardial infarction (ECCE). Herz. 1993;18 Suppl 1:424-9. PubMed PMID: 8125422. 
221. Yoshiji H, Kuriyama S, Fukui H. Angiotensin-I-converting enzyme inhibitors may be an alternative anti-angiogenic strategy in the treatment of liver fibrosis and hepatocellular carcinoma. Possible role of vascular endothelial growth factor. Tumour Biol 2002, 23:348-356.

222. Yasumatsu R, Nakashima T, Masuda M, Ito A, Kuratomi Y, Nakagawa T, Komune S. Effects of the angiotensin-I converting enzyme inhibitor perindopril on tumor growth and angiogenesis in head and neck squamous cell carcinoma cells. J Cancer Res Clin Oncol 2004, 130:567-573.

223. Miyajima A, Kosaka T, Asano T, Asano T, Seta K, Kawai T, Hayakawa M. Angiotensin II type I antagonist prevents pulmonary metastasis of murine renal cancer by inhibiting tumor angiogenesis. Cancer Res 2002; 62:4176-4179.

224. Hii SI, Nicol DL, Gotley DC, Thompson LC, Green MK, Jonsson JR. Captopril inhibits tumour growth in a xenograftmodel of human renal cell carcinoma. Br J Cancer 1998; 77:880-883.

225. Arrieta O, Pineda-Olvera B, Guevara-Salazar P, HernándezPedro N, Morales-Espinosa D, Cerón-Lizarraga TL, González-De la Rosa CH, Rembao D, Segura-Pacheco B, Sotelo J. Expression of AT1 and AT2 angiotensin receptors in astrocytomas is associated with poor prognosis. $\mathrm{Br} \mathrm{J}$ Cancer. 2008;99:160-6. doi: 10.1038/sj.bjc.6604431.

226. Arrieta O, Guevara P, Escobar E, García-Navarrete R, Pineda B, Sotelo J. Blockage of angiotensin II type 1 receptor decreases the synthesis of growth factors and induces apoptosis in C6 cultured cells and C6 rat glioma. Br J Cancer 2005;92:1247-1252.

227. Kosugi M, Miyajima A, Kikuchi E, Kosaka T, Horiguchi Y, Murai M. Effect of angiotensin II type 1 receptor antagonist on tumor growth and angiogenesis in a xenograft model of human bladder cancer. Hum Cell 2007;20:1-9.

228. Suganuma T, Ino K, Shibata K, Kajiyama H, Nagasaka T, Mizutani S, Kikkawa F. Functional expression of the angiotensin II type 1 receptor in human ovarian carcinoma cells and its blockade therapy resulting in suppression of tumor invasion, angio- genesis, and peritoneal dissemination. Clin Cancer Res 2005, 11:2686-2694.

229. Kosaka T, Miyajima A, Takayama E, Kikuchi E, Nakashima J, Ohigashi T, Asano T, Sakamoto M, Okita H, Murai M, Hayakawa M. Angiotensin II type 1 receptor antagonist as an angiogenic inhibitor in prostate cancer. Prostate 2007;67:41.

230. Puddefoot JR, Udeozo UK, Barker S, Vinson GP. The role of angiotensin II in the regulation of breast cancer cell adhesion and invasion. Endocr Relat Cancer 2006, 13:895903.

231. Neo JH, Malcontenti-Wilson C, Muralidharan V, Christophi C. Effect of ACE inhibitors and angiotensin II receptor antagonists in a mouse model of colorectal cancer liver metastases. J Gastroenterol Hepatol 2007, 22:577-584.

232. Huang W, Wu YL, Zhong J, Jiang FX, Tian XL, Yu LF. Angiotensin II type 1 receptor antagonist suppress angiogenesis and growth of gastric cancer xenografts. Dig Dis Sci 2008;53:1206-1210.

233. Juillerat-Jeanneret L, Celerier J, Chapuis Bernasconi C, Nguyen G, Wostl W, Maerki HP, Janzer RC, Corvol P, Gasc JM. Renin and angiotensinogen expression and functions in growth and apoptosis of human glioblastoma. Br J Cancer. 2004;90:1059-68.

234. Rivera E, Arrieta O, Guevara P, Duarte-Rojo A, Sotelo J. AT1 receptor is present in glioma cells; its blockage reduces the growth of rat glioma. Br J Cancer. 2001;85:1396-9.

235. Nakagawa T, Kubota T, Kabuto M, Kodera T. Captopril inhibits glioma cell invasion in vitro: involvement of matrix metalloproteinases. Anticancer Res. 1995;15(5B):1985-9. PubMed PMID: 8572589.

236. Sohn CA. Evaluation of ketoconazole. Clin Pharm. 1982;1:217-24.

237. Beetens JR, Loots W, Somers Y, Coene MC, De Clerck F. Ketoconazole inhibits the biosynthesis of leukotrienes in vitro and in vivo. Biochem Pharmacol. 1986;35:883-91. PubMed PMID: 3006695.

238. Nardone PA, Slotman GJ, Vezeridis MP. Ketoconazole: a thromboxane synthetase and 5-lipoxygenase inhibitor with antimetastatic activity in B16-F10 melanoma. J Surg Res. 1988;44:425-9. PubMed PMID: 3361885.

239. Tzanakakis GN, Krambovitis E, Tsatsakis AM, Vezeridis MP. The preventive effect of ketoconazole on experimental metastasis from a human pancreatic carcinoma may be related to its effect on prostaglandin synthesis. Int $\mathrm{J}$ Gastrointest Cancer. 2002;32:23-30. PubMed PMID: 12630766 .

240. Lelcuk S, Huval WV, Valeri CR, Shepro D, Hechtman HB. Inhibition ofischemia-induced thromboxane synthesis in man. J Trauma. 1984;24:393-6.PubMed PMID: 6325720.

241. Tolman EL, Fuller BL. Inhibition of thromboxane synthesis in guinea pig lung and human platelets by clotrimazole and other imidazole antifungals. Biochem Pharmacol. 1983;32:3488-90. PubMed PMID: 6316985.

242. Tzanakakis GN, Agarwal KC, Vezeridis MP. Inhibition of hepatic metastasis from a human pancreatic adenocarcinoma (RWP-2) in the nude mouse by prostacyclin, forskolin, and ketoconazole. Cancer. 1990;65:446-51. PubMed PMID:2404557.

243. Williams JG, Maier RV. Ketoconazole inhibits alveolar macrophage production of inflammatory mediators involved in acute lung injury (adult respiratory distress syndrome). Surgery. 1992;112:270-7. PubMed PMID: 1322565.

244. McManus M, Serhan C, Jackson P, Strange K. Ketoconazole blocks organic osmolyte efflux independently of its effect on arachidonic acid conversion. Am J Physiol. 1994;267(1 Pt 1):C266-71.

245. Venishetty VK, Komuravelli R, Kuncha M, Sistla R, Diwan PV. Increased brain uptake of docetaxel and ketoconazole loaded folate-grafted solid lipid nanoparticles. Nanomedicine. 2013;9:111-21 doi:10.1016/j. 
nano.2012.03.003

246. Yang ZH, Liu XD. P-glycoprotein-mediated efflux of phenobarbital at the blood-brain barrier evidence from transport experiments in vitro. Epilepsy Res. 2008;78:40-9. PubMed PMID: 18063342.

247. Kageyama M, Namiki H, Fukushima H, Ito Y, Shibata $\mathrm{N}$, Takada K. In vivo effects of cyclosporin $\mathrm{A}$ and ketoconazole on the pharmacokinetics of representative substrates for P-glycoprotein and cytochrome P450 (CYP) 3A in rats. Biol Pharm Bull. 2005;28:316-22. PubMed PMID: 15684491.

248. Choo EF, Leake B, Wandel C, Imamura H, Wood AJ, Wilkinson GR, Kim RB. Pharmacological inhibition of P-glycoprotein transport enhances the distribution of HIV1 protease inhibitors into brain and testes. Drug Metab Dispos. 2000;28:655-60. PubMed PMID: 10820137.

249. Eagling VA, Profit L, Back DJ. Inhibition of the CYP3A4mediated metabolism and P-glycoprotein-mediated transport of the HIV-1 protease inhibitor saquinavir by grapefruit juice components. Br J Clin Pharmacol. 1999;48:543-52. PubMed PMID: 10583025; PubMed Central PMCID: PMC2014377.

250. Gupta A, Unadkat JD, Mao Q. Interactions of azole antifungal agents with the human breast cancer resistance protein (BCRP). J Pharm Sci. 2007;96:3226-35. PubMed PMID: 17518356.

251. Chien RN, Yang LJ, Lin PY, Liaw YF. Hepatic injury during ketoconazole therapy in patients with onychomycosis: a controlled cohort study. Hepatology. 1997;25:103-7.

252. Hay RJ. Risk/benefit ratio of modern antifungal therapy: focus on hepatic reactions. J Am Acad Dermatol. 1993;29:S50-4.

253. Knight TE, Shikuma CY, Knight J. Ketoconazole-induced fulminant hepatitis necessitating liver transplantation. J Am Acad Dermatol. 1991;25(2 Pt 2):398-400.

254. Figg WD, Woo S, Zhu W, Chen X, Ajiboye AS, Steinberg SM, Price DK, Wright JJ, Parnes HL, Arlen PM, Gulley JL, Dahut WL. A phase I clinical study of high dose ketoconazole plus weekly docetaxel for metastatic castration resistant prostate cancer. J Urol. 2010;183:221926. doi: 10.1016/j.juro.2010.02.020.

255. Kim JA, Chung YJ, Lee YS. Intracellular Ca2+ mediates lipoxygenase-induced proliferation of U-373 MG human astrocytoma cells. Arch Pharm Res. 1998;21:664-70.

256. Wang B, Yu SC, Jiang JY, Porter GW, Zhao LT, Wang Z, Tan H, Cui YH, Qian C, Ping YF, Bian XW. An inhibitor of arachidonate 5-lipoxygenase, Nordy, induces differentiation and inhibits self-renewal of glioma stem-like cells. Stem Cell Rev. 2011;7:458-70. doi: 10.1007/s12015010-9175-9.

257. Ishii K, Zaitsu M, Yonemitsu N, Kan Y, Hamasaki Y, Matsuo M . 5-lipoxygenase pathway promotes cell proliferation in human glioma cell lines. Clin Neuropathol.
2009;28:445-52.

258. Lim JY, Oh JH, Jung JR, Kim SM, Ryu CH, Kim HT, Jeun SS. MK886-induced apoptosis depends on the 5-LO expression level in human malignant glioma cells. J Neurooncol. 2010;97(3):339-46. doi: 10.1007/s11060-0090036-9.

259. Zhang L, Zhang WP, Hu H, Wang ML, Sheng WW, Yao HT, Ding W, Chen Z, Wei EQ. Expression patterns of 5-lipoxygenase in human brain with traumatic injury and astrocytoma. Neuropathology. 2006;26(2):99-106.

260. Chio CC, Baba T, Black KL. Selective blood-tumor barrier disruption by leukotrienes. J Neurosurg. 1992;77:407-10.

261. Shinonaga M, Chang CC, Kuwabara T. Relation between macrophage infiltrates and peritumoral edema. Adv Neurol. 1990;52:475-81.

262. Black KL, Hoff JT, McGillicuddy JE, Gebarski SS Increased leukotriene $\mathrm{C} 4$ and vasogenic edema surrounding brain tumors in humans. Ann Neurol. 1986;19:592-5.

263. Simmet T, Luck W, Winking M, Delank WK, Peskar BA. Identification and characterization of cysteinyl-leukotriene formation in tissue slices from human intracranial tumors: evidence for their biosynthesis under in vivo conditions. $\mathrm{J}$ Neurochem. 1990;54:2091-9.

264. Gàti I, Bergström M, Westerberg G, Csòka K, Muhr C, Carlsson J. Effects of prostaglandin and leukotriene inhibitors on the growth of human glioma spheroids. Eur J Cancer. 1990;26:802-7. PubMed PMID: 2145898.

265. Gáti I, Bergström M, Muhr C, Carlsson J. Leukotriene and 5-lipoxygenase inhibitor induced variations in thymidine uptake in a human glioma cell line cultured as monolayers or as multicellular spheroids. Anticancer Res. 1994;14(2A):453-9. PubMed PMID: 8017847.

266. Golubic M, Prayson RA, Vargo L, Bondar J, Barnett GH. Increased expression of 5-lipoxygenase in glioblastoma multiforme. Adv Exp Med Biol. 2003;525:205-8.

267. Nathoo N, Prayson RA, Bondar J, Vargo L, Arrigain S, Mascha EJ, Suh JH, Barnett GH, Golubic M. Increased expression of 5-lipoxygenase in high-grade astrocytomas. Neurosurgery. 2006;58:347-54.

268. Castelli MG, Butti G, Chiabrando C, Cozzi E, Fanelli R, Gaetani P, Silvani V, Paoletti P. Arachidonic acid metabolic profiles in human meningiomas and gliomas. J Neurooncol. 1987;5:369-75.

269. Murphy S, Welk G, Thwin SS. Stimulation of thromboxane release from primary cell cultures derived from human astrocytic glioma biopsies. Glia 1990;3:205-11. PubMed PMID: 2141596.

270. Takano S, Ishimoto $\mathrm{H}$, Nakahata $\mathrm{N}$, Nakanishi $\mathrm{H}$. Thromboxane A2 receptor characterization in human astrocytoma cells and rabbit platelets by a new thromboxane antagonist, [3H]ONO NT-126. Res Commun Chem Pathol Pharmacol. 1999;76:155-70. PubMed PMID: 1534919.

271. Nakahata N, Matsuoka I, Ono T, Nakanishi H. Thromboxane $\mathrm{A} 2$ activates phospholipase $\mathrm{C}$ in astrocytoma 
cells via pertussis toxin-insensitive G-protein. Eur J Pharmacol. 1989;162:407-17. PubMed PMID: 2545456.

272. McDonough W, Tran N, Giese A, Norman SA, Berens ME. Altered gene expression in human astrocytoma cells selected for migration: I.Thromboxane synthase. J Neuropathol Exp Neurol. 1998;57:449-55.

273. Schmidt NO, Ziu M, Cargioli T, Westphal M, Giese A, Black PM, Carroll RS. Inhibition of thromboxane synthase activity improves glioblastoma response to alkylation chemotherapy. Transl Oncol. 2010;3(1):43-9.

274. Schauff AK, Kim EL, Leppert J, Nadrowitz R, Wuestenberg $\mathrm{R}$, Brockmann MA, Giese A. Inhibition of invasionassociated thromboxane synthase sensitizes experimental gliomas to gamma-radiation. J Neurooncol. 2009;91:241-9. doi: 10.1007/s11060-008-9708-0.

275. Yoshizato K, Zapf S, Westphal M, Berens ME, Giese A. Thromboxane synthase inhibitors induce apoptosis in migration-arrested glioma cells. Neurosurgery. 2002;50:343-54.

276. Ekambaram P, Lambiv W, Cazzolli R, Ashton AW, Honn $\mathrm{KV}$. The thromboxane synthase and receptor signaling pathway in cancer: an emerging paradigm in cancer progression and metastasis. Cancer Metastasis Rev. 2011;30:397-408. doi: 10.1007/s10555-011-9297-9.

277. Gallagher P, Malik N, Newham J, Young AH, Ferrier IN, Mackin P. Antiglucocorticoid treatments for mood disorders. Cochrane Database Syst Rev. 2008;(1):CD005168. doi:10.1002/14651858.CD005168. pub2.

278. Reist C, Wu JC, Lilja Y, Mukherjee J, Gripeos D, Constantinescu C, Raggi MA, Mercolini L, Ozdemir V. Ketoconazole-associated preferential increase in dopamine D2 receptor occupancy in striatum compared to pituitary in vivo: role for drug transporters? J Clin Psychopharmacol. 2012;32:110-3. doi:10.1097/JCP.0b013e3182408fc8.

279. FDA.gov http://www.fda.gov/Drugs/DrugSafety/ drugSafetyInformationforPatientsandProviders/ucm111085. htm

280. Sanchez RI, Wang RW, Newton DJ, Bakhtiar R, Lu P, Chiu SH, Evans DC, Huskey SE. Cytochrome P450 3A4 is the major enzyme involved in the metabolism of the substance $\mathrm{P}$ receptor antagonist aprepitant. Drug Metab Dispos. 2004;32(11):1287-92.

281. EMENDTM SPC, (accessed January, 2012) http:// www.accessdata.fda.gov/drugsatfda_docs/ label/2009/021549s016lbl.pdf

282. Granfors MT, Wang JS, Kajosaari LI, Laitila J, Neuvonen PJ, Backman JT. Differential inhibition of cytochrome P450 3A4, 3A5 and $3 \mathrm{~A} 7$ by five human immunodeficiency virus (HIV) protease inhibitors in vitro. Basic Clin Pharmacol Toxicol. 2006;98:79-85.

283. Piscitelli SC, Gallicano KD. Interactions among drugs for HIV and opportunistic infections. N Engl J Med. 2001;344:984-96.
284. van Agtmael MA, Eggelte TA, van Boxtel CJ. Artemisinin drugs in the treatment of malaria: from medicinal herb to registered medication. Trends Pharmacol Sci. 1999;20:199205.PubMed PMID: 10354615.

285. Coartem product information. Novartis at http://www. coartem.com/coartem-riamet.htm

286. Velayudham LS, Farrell GC. Drug-induced cholestasis. Expert Opin Drug Saf. 2003;2:287-304.

287. Bruno R, Sacchi P, Maiocchi L, Zocchetti C, Filice G. Hepatotoxicity and nelfinavir: a meta-analysis. Clin Gastroenterol Hepatol. 2005;3:482-8.

288. Sarganas G, Orzechowski HD, Klimpel A, Thomae M, Kauffmann W, Herbst H, Bronder E, Garbe E. Severe sustained cholestatic hepatitis following temozolomide in a patient with glioblastoma multiforme: case study and review of data from the FDA adverse event reporting system. Neuro Oncol. 2012;14:541-6. doi: 10.1093/neuonc/ nos056.

289. Rolling T, Schmiedel S, Wichmann D, Wittkopf D, Burchard GD, Cramer JP. Post-treatment haemolysis in severe imported malaria after intravenous artesunate: case report of three patients with hyperparasitaemia.Malar J. 2012;11:169. doi: 10.1186/1475-2875-11-169.

290. Liu C, Liu Z, Li M, Li X, Wong YS, Ngai SM, Zheng W, Zhang Y, Chen T. Enhancement of auranofin-induced apoptosis in MCF-7 human breast cells by selenocystine, a synergistic inhibitor of thioredoxin reductase. PLoS One. 2013;8(1):e53945. doi: 10.1371/journal.pone.0053945.

291. Schuh E, Pflüger C, Citta A, Folda A, Rigobello MP, Bindoli A, Casini A, Mohr F. Gold(I) carbene complexes causing thioredoxin 1 and thioredoxin 2 oxidation as potential anticancer agents. J Med Chem. 2012;55:5518-28. doi:10.1021/jm300428v.

292. Cho HJ, Lee TS, Park JB, Park KK, Choe JY, Sin DI, Park YY, Moon YS, Lee KG, Yeo JH, Han SM, Cho YS, Choi MR, Park NG, Lee YS, Chang YC. Disulfiram suppresses invasive ability of osteosarcoma cells via the inhibition of MMP-2 and MMP-9 expression. J Biochem Mol Biol. 2007;40:1069-76. PMID: 18047805.

293. Shian SG, Kao YR, Wu FY, Wu CW. Inhibition of invasion and angiogenesis by zinc-chelating agent disulfiram. Mol Pharmacol. 2003;64:1076-84. PubMed PMID: 14573756.

294. Newman B, Liu Y, Lee HF, Sun D, Wang Y. HSP90 inhibitor 17-AAG selectively eradicates lymphoma stem cells. Cancer Res. 2012;72(17):4551-61. doi:10.1158/00085472.CAN-11-3600.

295. Sobhan PK, Seervi M, Joseph J, Chandrika BB, Varghese S, Santhoshkumar TR, Radhakrishna Pillai M. Identification of heat shock protein 90 inhibitors to sensitize drug resistant side population tumor cells using a cell based assay platform. Cancer Lett. 2012;317:78-88. doi:10.1016/j. canlet.2011.11.009.

296. Tatokoro M, Koga F, Yoshida S, Kawakami S, Fujii Y, Neckers L, Kihara K. Potential role of Hsp90 inhibitors in 
overcoming cisplatin resistance of bladder cancer-initiating cells. Int J Cancer. 2012;131:987-96. doi:10.1002/ijc.26475.

297. He Y, Fan J, Lin H, Yang X, Ye Y, Liang L, Zhan Z, Dong $\mathrm{X}$, Sun L, Xu H. The anti-malaria agent artesunate inhibits expression of vascular endothelial growth factor and hypoxia-inducible factor- $1 \alpha$ in human rheumatoid arthritis fibroblast-like synoviocyte. Rheumatol Int. 2011;31:53-60. doi: 10.1007/s00296-009-1218-7.

298. Kast RE, Foley KF, Focosi D. Doxorubicin cardiomyopathy via TLR-2 stimulation: potential for prevention using current anti-retroviral inhibitors such as ritonavir and nelfinavir. Hematol Oncol. 2007;25:96-7. PubMed PMID: 17351982.

299. Casini A, Messori L. Molecular mechanisms and proposed targets for selected anticancer gold compounds. Curr Top Med Chem. 2011;11:2647-60. PMID: 22039866

300. Weir SJ, DeGennaro LJ, Austin CP. Repurposing approved and abandoned drugs for the treatment and prevention of cancer through public-private partnership. Cancer Res. 2012;72:1055-8. doi: 10.1158/0008-5472.CAN-11-3439.

301. Multhoff G, Radons J. Radiation, inflammation, and immune responses in cancer. Front Oncol. 2012;2:58. doi: 10.3389/fonc. 2012.00058 .

302. Multhoff G, Molls M, Radons J. Chronic inflammation in cancer development. Front Immunol. 2011;2:98. doi: 10.3389/fimmu.2011.00098.

303. Randle JC, Harding MW, Ku G, Schönharting M, Kurrle R. ICE/Caspase-1 inhibitors as novel anti-inflammatory drugs. Expert Opin Investig Drugs. 2001;10:1207-9.

304. Sethi G, Shanmugam MK, Ramachandran L, Kumar AP, Tergaonkar V. Multifaceted link between cancer and inflammation. Biosci Rep. 2012;32:1-15. doi: 10.1042/ BSR20100136.

305. Sgambato A, Cittadini A. Inflammation and cancer: a multifaceted link. Eur Rev Med Pharmacol Sci. 2010;14:263-8.

306. Yeh WL, Lu DY, Liou HC, Fu WM. A forward loop between glioma and microglia: glioma-derived extracellular matrix-activated microglia secrete IL-18 to enhance the migration of glioma cells. J Cell Physiol. 2012;227:558-68. doi: 10.1002/jcp.22746.

307. Kaluz S, Van Meir EG. At the crossroads of cancer and inflammation: Ras rewires an HIF-driven IL-1 autocrine loop. J Mol Med (Berl). 2011;89:91-4.doi: 10.1007/s00109010-0706-2. PubMed PMID: 21161499.

308. Wolff JE, Brown RE, Buryanek J, Pfister S, Vats TS, Rytting ME. Preliminary experience with personalized and targeted therapy for pediatric brain tumors. Pediatr Blood Cancer. 2012;59:27-33. doi: 10.1002/pbc.23402.

309. Khoshnevisan A. An overview of therapeutic approaches to brain tumor stem cells. Med J Islam Repub Iran. 2012;26:31-40. PMID: 23483074

310. Mantamadiotis T, Taraviras S. Self-renewal mechanisms in neural cancer stem cells. Front Biosci. 2011;16:598-607.
311. Phillips JJ. Novel therapeutic targets in the brain tumor microenvironment. Oncotarget. 2012;3:568-75. PMID: 22643827.

312. Hideki Yamaguchi, Tsukasa Oikawa. Membrane lipids in invadopodia and podosomes: Key structures for cancer invasion and metastasis. Oncotarget. 2010; 1: 320-328. PMC3157727

313. Wolf A, Agnihotri S, Guha A. Targeting metabolic remodeling in glioblastoma multiforme. Oncotarget. 2010; 1: 567-577. PMC3248131

314. Nogueira L, Ruiz-Ontañon P, Vazquez-Barquero A, Moris F, Fernandez-Luna JL. The NFkB pathway: a therapeutic target in glioblastoma. Oncotarget. 2011;2:646-53. 